nivj a no

$+$

UCRL 93431

PREPRIIT

\title{
A Ground Reaction Curve Based Upon Block Theory
}

Jesse L. Yow, Jr.

Richard E. Goodman

\section{4th Geomechanics Colloquy Austrian Society for Geomechanics \\ Salzburg, Austria \\ October 10-11, 1985}

\section{September 1985}

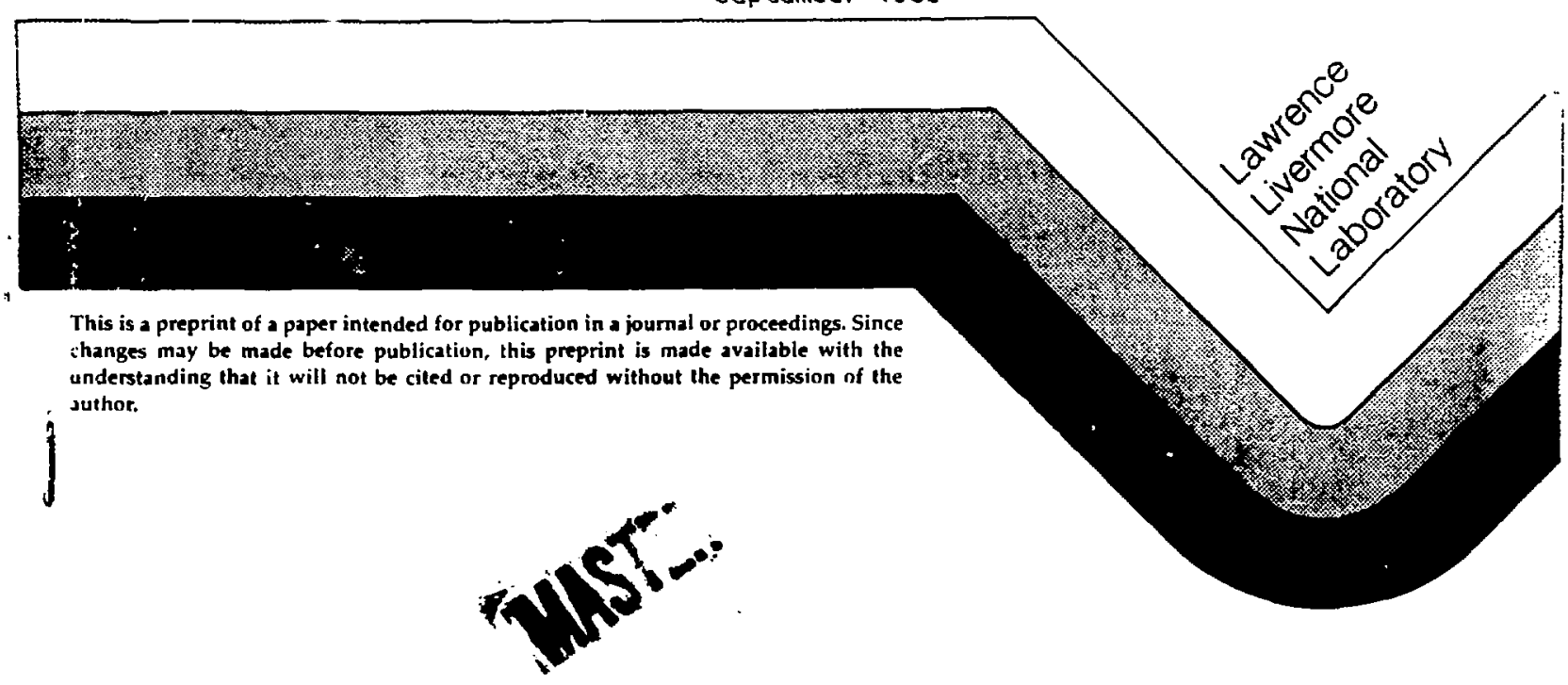


UCRL -93431

Discontinuities in a rock mass can intersect an excavation surface to form discrete blocks (keyblocks) which can be unstable. Once a potentially unstable block is identffied, the forces affecting it can be calculated to assess its stabllity. The normal and shear stresses on each block face before displacement are calculated using elastic theory and are modified in a nonlinear way by discontinuity deformations as the keyblock displi es. The stresses are sumed into resultant forces to evaluate block stability. Since the resultant forces change with displacement, successive increments of block movement are examined to see whether the block ultimately becomes stable or fatis.

Two-dimensional (2D) and three-dimensional (30) analytic models for the stablitity of simple pyranidal keyblocks were evaluated. Calculated stability is greater for 30 analyses than for 2D analyses. Calculated keyblock stablity fincreases with larger in situ stress magnitudes, larger lateral stress ratios, and larger shear strengths. 0iscontinutty stiffness controls block displacement more strongly than it does stability itself. Large keyblocks are less stable than small ones, and stabiltty increases as blocks become more slender.

$$
\text { V }
$$

Prepared by Nevade Nuclear Warte Storaze Investientions (NNWST) Project perticipante as part of the Civilian Radionetive Weste Managemeat Prograra. The NNwSI Project is maneged by the Warte Management Project Office of the U.S. Department of Enerw. Nevada Operations Office. NNWSI Project work is sponsored by the Orfice of Geologic Reposttorite of the DOE Office of Civilien Radionctive Waste Manasement. 


\section{DISCLAIMER}

This report was prepared as an account of work sponsored by an agency of the United States Government. Neither the United States Government nor any agency thereof, ner any of their employees, makes any warranty, express or implied, or assumes any legal liability or responsibility for the accuracy, completeness, or useiulness of any information, appasatus, product, or process disclosed, or represents that its use would not infringe privalely owned rights. Reference herein to any specific commercial product, process, or service by trade name, Irademark, manufacturer, or otherwise does not necessarily constitute or imply is endorsement, recommendation, or favoring by the United States Government or any agency thereof. The views and opinions of authors expressed herein do not recessarily state or rehlect those of the United States Government or any agency thereor. 


\section{INTRODUCTION}

Rock masses in which excavations are constructed almost always contain discontinuities such as joints, shears, and faults. Often, these discontinuities will intersect to create blocks of rock in the perimeter of an excavation. These blocks can have shapes so as to be able to displace into the excavation, unobstructed by adjacent rock. Blocks of more complex shape may be encountered, but are usually formed by combinations of geometrically simpler blocks (Goodman and Sh1, 1985). The behavior and stability of these relatively simple blocks is therefore a problem of fundamental interest in the design and use of underground e:tcavations.

Conventional design approaches for excavation stabllity analys is usually include assumptiors regarding the rock mass and its properties. Figure 1 1llustrates common ways of treating the rock mass in calculations of excavation stablitity or deformation. Figure la shows a tunnel sited in a continuous rock mass, 1.e., rock containing no discontinuities. This allows continuum methods of elasticity to be used in elther closed form expresstons or finite element approaches to estimate stresses and deformations around the excavation. Since rock is usualiy discontinuous, this approach is a simp?ification that of ten underestimates excavation deformations and does not allow all possible fallure modes to be addressed.

* Hork performed under the auspices of the U.S. Department of Energy by the 
Figure ib shows a tunnel in rock containing a single ubiquitous set of discontinutites; this concept can be used with closed form solutions (Daemen, 1983) or with finite element schemes to locate and determine the size of zones around the excavation in which sitp is expected to occur as construction or post-construction loading proceeds. Scoping calculations can be readily made with this type of mode1; the results are useful to get an overall impression of the 1 imits of opening behavior.

Figure lc 11lustrates a tunnel in a rock mass containing several discrete discontinuities. Like the ubiquitous discontinuities, this can be examined with a finite element method of analysis to obtain excavation behavior estimates for specific situations (e.g.. Heuze et a1, 1982). However, a considerable amount of information on the discontinutty and excavation geometries is needed, and each situation to be analyzed requires setting up a new finfte element mesh for the numertcal code that is used for the solution.

Figure 1d shows a tunne? in rock coiltaining discontinulties that intersect to form keyblocks. This paper presents an approach for solving this class of problems which is intended to compiement rather than replace the three preceding methods of analysis. Each of the three preceding methods can be readily used for a two-dimensional analysis or, wth some difficulty, a three-dimensional analysis. However, the keyblock approach allows keyblocks in three dimenstons to be identifted using procedures developed by Goodman and Sh1 (1981), and allows the stablitty and displacement behavior of keyblocks to be estimated using methods developed here. The calculations involved are simple enough to allow use of the method for general scoping calculations as well as for analysis of specific problems. 
When a kinematically removable block (keyblock or potentlal keyblcck) has been identified, its stability must be evaluated so that the excavation design can include any ground support measures that are needed to maintain the integrity of the opening. In general, block behavior is influenced by the shear strength of the discontinuities forming the keyblock, the initial stresses acting on the block faces, the changes in stresses that occur as the block displaces, and the block geometry. Stress changes are a function of discontinuity dilatancy, normal and shear stiffnesses, and block displacement. Keyblock geometry includes block height and width, block location around the excavation perimeter, displacement direction, and block size with respect to the size of the opening. Inspection of Table 1, which lists the analytical approaches of previous investigators, reveals that not all of these factors have been addressed by earlier models.

Different approaches have been taken by the models listed in Table 1 in the ways in which they evaluate keyblock behavior. In particular, there is a significant difference in whether or not a model provides for adjustments in stresses as the block moves towards fallure. Models that do not account for stress changes typically do not include discontinuity stiffnesses or dllatancy, or keyblock displacement. Since some displacement is usually required in order to mobilize shear stresses to help resist block fallure, these models do not evaluate keyblock behavior under realistic shear stress conditions. Such mode 15 are thus conservative in their approach to ground support needs. Analytic models that do account for stiffness use different methods of solution; some calculate keyblock displacement corresponding to a 
Table 1 Analytical Models for Keyblock Stability

\begin{tabular}{|c|c|c|c|c|}
\hline \multirow[b]{2}{*}{ Investigator } & \multirow{2}{*}{$\begin{array}{c}\text { Block } \\
\text { Geometry }\end{array}$} & \multirow{2}{*}{$\begin{array}{l}\text { Initial } \\
\text { Stresses }\end{array}$} & \multicolumn{2}{|c|}{ Discontinuity } \\
\hline & & & atanry. & Stiffness \\
\hline Benson et a 1,1971 & 20 & not used & no & no \\
\hline Cording et a1, 1971 & 20 & assumed $^{(2)}$ & no & no \\
\hline Goodman, 1976 & 30 & not used & no & no \\
\hline Hoek, 1977 & 30 & not used & no & no \\
\hline Croney et a1, 1978 & 30 & as sumed $(2)$ & no & no \\
\hline Bray, $1979^{(3)}$ & 20 & tangent to opening & no & linear \\
\hline Cortc, 1979 & 30 & assumed $(2)$ & no & no \\
\hline Hoek \& Brown, 1980 & 30 & not used & no & no \\
\hline Warburton, 1981 & 30 & not used & no & no \\
\hline Crawford, 1982 & 20 & tangent to opening & no & 11near \\
\hline Goodman et al, 1982 & 30 & tangent to opening & yes & linear \\
\hline Zhu \& Zhizhong, 1982 & 20 & as sumed $^{(2)}$ & no & no \\
\hline Crawford \& Bray, 1983 & 20 & tangent to opening & no & 11near \\
\hline Elsworth, $1983^{(4)}$ & 20 & 2D hydrostatic & yes & 1inear \\
\hline Zhtfa, 1983 & 30 & as sumed $(2)$ & no & no \\
\hline Belytschko et a1, 1983 & 20 & as sumed $^{(2)}$ & no & no \\
\hline Boyle, work in progress & 30 & tangent to opening & yes & 11near \\
\hline Yow, 1985 & 30 & 30 & yes & $\begin{array}{l}\text { 1inear or } \\
\text { non-1inear }\end{array}$ \\
\hline
\end{tabular}

NOTES: (1) Initial stresses are those affecting block before displacement. A11 modeis include friction and block weight.

(2) Inttial stresses on block faces assumed from separate stress analysis.

(3) Unpublished notes by John Bray.

(4) Elsworth, D., 1983, "Wedge Stab1ilty in the Roof of a Circular Cross Section Underground Opening - Plane Strain Condition," 20 pp. Unpublished report, Department of Civt1 Engineering (Geological Engineering). University of California, Berkeley. 
specified set of stress conditions, while others ralculate the stresses and resultant forces caused by a specified displacement. In either case, the problem is examined parametrically to see if equilibrium can be reached under In situ conditions.

\section{Stab1lity Ana lys is Assumptions}

figure id fllustrated in two dimensions some of the assumptions that are needed for the methods of analysis developed here. A tunnel or excavation, circular in section, is sited in a rock mass that contains planar discontinuities. The discontinuities themselves are unhealed and are extensive enough that they intersect to form simple, pyramidal keyblocks. Figure 2 shows a typical pyramidal block in three dimensions. The ctrcular tunnel section is appropriate for tunnels excavated by boring machines, and is in some cases a reasonable approximation for tunnels of other shapes.

The circular tunnel section allows the use of the Kirsch solution (Goodman, 1980) for calculating initial stresses in two-dimensional analyses. A solution by Amadei (1982) can be used for initial stresses in three-dimensional analyses. The solutions are based on elastic theory; these procedures can be used in numerical models for an expedient estimate of initial stresses around the excavation prior to any displacements along discontinuities. Other investigators have used finite element codes to calculate initial stress values (e.g.. Croney et a1., 1978), but this makes the analysis cumbersome in evaluating a range of in situ conditions. 
Finally, in order to be able to define discontinuity deformation behavior, the rock mass is assumed to deform as a system of springs of varying stiffnesses. The rock that forms the keyblock and its surroundings is taken to be very stiff in comparison to the discontinuities and all displacement is assumed to occur along discontinuities. A spring system is illustrated in Figure 3 for deformation of a jointed rock in one dimension. Such a conceptual approach is described by Goodman (7976 and 1980); its application will be developed below in the discussion of discontinuity characteristics.

\section{Keyblock Instability and Displacement}

Keyblocks can fail in a translational mode either by falling or by sliding. Rotational block fallure such as toppling is beyond the scope of this work. If a keyblock falls, separation occurs on all of the keyblock faces simultaneously. Alternatively, sliding can occur on either one or two block faces to allow these faces to remain in contact during fallure.

There are practical limits on the displacement that can be expected of a kes'slock before either a condition of stability is reached under prevaliting conditions, or the keyblock completely fails. These limits can be used as a practical check on the performance of a keyblock behavior model to detect unrealistic results caused by errors in the data or the computations. The lower limits of keyblock displacement correspond to the elastic deformation calculated for a similar excavation in continuous rock. Two-dimensional plane strain equations or computing radial deformation of a circular tunnel in an elastic rock without discontinulties can be found in texts by Goodman (7980) and by Obert and Duval (1967). 
Conversely, upper limits on keyblock displacement magnitude can be approximated from estimates of the displacement necessary to mobilize the peak shear sirengths of the discontinutties that bound the block. This presumes that the keyblock falls once all avallable peak shear strengths have been surpassed. Barton and Choubey (1977) have suggested that peak strength is reached after a shear dispiacement of about one percent of the discontinuity length as measured in the direction of sliding. Since discontinuity length will depend on keyblock and excavation geometry, an average length based on the height from the excavation to the block apex should suffice for estimating displacement magnitudes.

\section{Discontinutty Shear Strength}

Two discontinuity characteristics, strength and stiffness, must be considered in order to properly calculate the stablitity of a keyblock. The discontinutty shear strengths limit the shear stresses which can act on block surfaces in contact with adjacent rock, and ultimately govern whether or not the keyblock can be stable as situated. The normal and shear stiffnesses in turn control the changes in discontinutty stresses that are induced by keyb lock displacement.

The shear strength of an unhealed discontinutity can be represented as a combination of a friction angle $\left(\phi^{\circ}\right)$ for a smooth rock surface and a dilatancy angle $\left(1^{\circ}\right)$ for the discontinutty surface roughness. If the shear strength is assumed to vary linearly with the normal stress, it can be calculated as:

$$
\tau_{a}=\sigma_{n} \tan (1+\phi)
$$


In this expression $\tau_{a}$ is the avallable shear strength and $\sigma_{n}$ is the norma 1 stress on the discontinuity. Dllatancy also affects changes in normal stress during displacement, as wili be explained below.

Barton and Choubey (1977) have given an expression that represents a nonlinear vartation of discontinuity shear strength as a function of norma 1 stress, surface strength, and surface roughness:

$$
\tau_{a}=\sigma_{n} \tan \left(J R C \log _{10}\left(\frac{J C S}{\sigma_{n}}\right)+\phi_{r}\right)
$$

JRC is the joint roughness coefficient, which is a measure of surface roughness. JCS is the joint compressive strength, which is a measure of the strength of the asperities that make the discontinuity surface rough. $\phi_{r}$ is a residual friction angle that Barton and Choubey relate empirically to \$. Note that the nonlinear equation can be divided into a dilatancy component and a friction component. The dilatancy component becomes smaller as the normal stress increases, reflecting fallures of asperities during shear. Either the linear or the nonlinear strength equations can be used in keyblock stability models that were developed, coded, and listed by Yow (1985).

\section{Discontinuity Stiffness}

The normal stiffness $k_{n}$ of a discontinuity can be defined as the change in normal stress that occurs with a given change in discontinuity thickness (aperture opening or closure). Simtlarly, shear stiffness $k_{s}$ is the change of shear stress that results from an incremental amount of shear displacement. 
If a load is applied normal to a discontinuity contained in a rock specimen (Figure 3 ) the resulting deformation in one dimension represents the sum of the deformation of the intact rock and the deformation of the discontinuity (Figure 4). A jointed rock mass can thus be thought of in a one-dimensional sense as a sequence of springs that act in series. Assuming isotropic, linear elastic rock, the rock is represented by very stiff, linear spring behavior while discontinuities are represented by initially softer, highly nonlinear springs. Correspondingly, the tota 1 rock mass deformability and its components are:

$$
\frac{1}{E_{m}}=\frac{1}{E}+\frac{1}{k_{n} S}
$$

In this equation, $E_{m}$ is the modulus of deformation curve of the rock mass, $E$ is the elastic modulus of the intact rock, $k_{n}$ is the normal stiffness of a discontinuity, and $S$ is the average discontinutty spacing.

Inspection of the discontinuity deformation plotted in figure 5 reveals that the curve asymptotically approaches a vertical slope as the normal load increases. The vertical line has been designated by Goodman (1976) as the maximum closure of the discontinutiy. Although the nonlinear deformation curve can be represented with a hyperbolic equation, Figure 5 shows how the normal stiffness can be approximated with two straight line segments. This useful engineering approximation is avallable in the keyblock stability models and requires as input a single value for $k_{n}$. A more ccrrect approach that is described below is also avallable (as an option) in these models. 
Bandis et al (1983) compared mathematical models that have been suggested for the nonilnear normal stiffness of foints with the results of stiffness tests conducted on discontinulty samples from different rock types. They propose a hyperbolic model for nonlinear behavior in the following form:

$$
\sigma_{i j}=\frac{\Delta V}{a-b \Delta V}
$$

where $\sigma_{n} \quad=$ normal stress on the discontinuity, and $\Delta V \quad=$ discontinutty closure.

The coefficients $a$ and $b$ can be obtained by rewriting equation 4 and considering the $11 \mathrm{miting}$ extremes of discontinuity closure at very large and very small normal stresses:

$$
a_{n}=\frac{1}{\frac{a}{\Delta V}-b}=\frac{1 / a}{\frac{1}{\Delta V}-\frac{b}{a}}
$$

Large normal stresses imply that the discontinutty closure $\Delta V$ approaches the maximum closure $V_{m}$. Therefore, as the normal stress goes to infinity, $2 / b=V_{m}$. Conversely, low normal stresses imply that $\Delta v$ goes to zero. In this case I/AV hecomes much larger than $b / a$, and the latter term can be dropped. Thus, $1 / a=k_{n 1}$, where $k_{n 1}$ is the initial normal stiffness.

Once the ceefficients $a$ and $b$ in equations 4 and 5 are defined, equation 5 can be changed into an expression for discontinuity closure:

$$
\Delta v=\frac{\sigma_{n}-v_{m}}{k_{n i} v_{m}+\sigma_{n}}
$$


The slope of the deformation curve (Figure 5) represents the normal stiffness of the discontinulty. Since the stiffness varies nonlinearly with normal stress, it can be found from the derivative of equation 4 with respect to joint closure:

$$
k_{n}=\frac{k_{n t}}{\left(1-\frac{\Delta v}{v_{m}}\right)^{2}}
$$

The preceding hyperbolic model for discontinuity normal stiffness (equations 4 through 7) was developed by Bandis et al (1983). These equations can, however, be used with equation 3 to derive an estimate of $k_{n}$ under in situ stress conditions before the excavation is created. This estimate can then be used with the hypertolic stiffness equation, enabling nonlinear discontinuity deformation to be included in the stability calculations. In the following equations the maximum discontinuity closure $V_{m}$ is replaced by the discontinuity aperture under no-load conditions (negligible normal stress). $a_{0}$.

Equation 7 can be rewritten to solve for $k_{n i}$ as follows:

$$
k_{n 1}=k_{n}-\frac{2 k_{n} \Delta V}{a_{0}}+k_{n} \frac{\Delta v^{2}}{a_{0}^{2}}
$$

Equation 6 can be rearranged and $k_{n 1}$ can be substituted from 8 to obtain an expression relating normal stress, normal stiffness, discontinuity no-load aperture, and discontinuity closure: 


$$
\Delta v\left(a_{0} k_{n}-2 \Delta v k_{n}+\frac{\Delta v^{2}}{a_{0}} k_{n}+\sigma_{n}\right)=\sigma_{n} a_{0}
$$

Finally, equation 9 can be modified into a third degree polynomial which can be solved for the ratio of discontinutty closure to no-load aperture under ambient in situ conditions:

$$
k_{n}\left(\frac{\Delta V}{a_{0}}\right)^{3}-2 k_{n}\left(\frac{\Delta V}{a_{0}}\right)^{2}+\left(\frac{\sigma_{n}}{a_{0}}+k_{n}\right)\left(\frac{\Delta V}{a_{0}}\right)-\frac{\sigma_{n}}{a_{0}}=0
$$

The non-trivial solutions of equation 10 include two possible values for the discontinuity closure as a fraction of total maximum closure. Inspection of a representative curve (Figure 5) for discontinuity normal deformation reveals that aperture closure will typically be greater than 50\% for most initial in situ stresses of interest. If the smaller closure value is selected, $k_{n i}$ must be very close to the in situ $k_{n}$. implying that either the in situ stresses are very low (low $k_{n}$ ) or that the discontinuity is very stiff (high $\left.k_{n i}\right)$. The larger of the two closure values is arbitiarily used to represent the condition of the discontinuity before the underground opening is excavated or keyblock displacement occurs.

Once equation 10 has been solved, the ratio of closure to aperture can be used in equation 8 to calculate $k_{n i}$. The coefficients a and $b$ can then be determined, and equation 5 can be used to obtain norma 1 stresses as the discontinuity forming the keyblock face opens or closes.

Figure 5 includes a typical nonlinear curve that relates normal load and displacement. This curve was generated with equation 5, which completely 
defines the curve from values of $a, b$, and $k_{n 1}$. This is implemented as an optional alternative to the linear approximation for normal stiffness in the keyblock behavior models. It should be noted that the discontinuity aperture used as a reference for joint opening or closing during block displacement is calculated from equation 6 using the modifled in situ stresses around the underground opening, as explained below.

The use of equation 10 requires values for the normal stress on the discontinuity, discontinuity normal stiffness at the given stress level, and initial (no-load) discontinuity aperture. Principal stresses that affect the discontinutty can be estimated from overburden depth, or may be avallable from on-site measurements. The stresses can then be rotated to find normal and shear stresses on each discontinutty plane using procedures outlined by Goodman (1980). Initial discontinuity apertures can be assumed, or estimated from an empirical equation provided by Bandis et al (1983). However, the normal stiffness of the discontinuity under the ambient stress condtions is difficult to estimate because of its variability.

If we treat the discontinuities that create keyblocks as members of sets, examine only one set at a time, and assume that the discontinuities of a set have an average spacing, we can rearrange equation 3 as follows to obtain an estimate of $k_{n}$ :

$$
k_{n}=\frac{E / S}{\left(E / E_{m}\right)-1}
$$

Such an estimate represents an average $k_{n}$ for the discontinulty set under the stress conditions that exist before the underground opening is excavated. Values are required for the average discontinuity spacing, the modulus of the 
intact rock; and the ratio of the rock mass deformability to the intact rock deformablitty. Discontinuity spacings and the modulus of deformation for Intact rock can be measured during site investigaitions, but now the difficulty lies in estimating the ratio of the deformation modul1. Heuze (1980) has suggested that the ratio of rock mass to intact rock deformation moduli can often be assumed as 0.4 . Alternatively. the in situ modulus can be estimated from correlations with rock mass classification schemes. With estimates or with fleld measurements, the nonlinear normal stiffness of each block face can now be quantifled.

Discontinuity shear stiffness is used to modify the shear stresses acting on the keyblock faces that are created by discontinutties. Before any block displacement occurs, the stresses on the block faces are determined by the stress field around the underground opening. When keyblock displacement comences, the shear stresses increase on each bounding discontinuity in accord with its shear stiffness unt 11 the maximum avallable shear strength is reached. However, the normal stress is usually dropping as displacement occurs, and so the peak avaflable strength may be reached almost immediately. Either of two approaches can be used to represent the shear stiffness, corresponding to the 1 inear and nonlinear definitions of normal stiffness developed above.

For the linear representation, a constant ratio of shear stiffness to normal stiffness can be used. This approximation for shear deformation is a constant stiffness model that assumes elastic behavior as described by Goodman (1976). Goodman et al (1982) examined a range of linear stiffness ratios in an analysis of a keyblock subjected to a tangential stress fleld in a planar 
excavation roof. They found that the stability of the keyblock was less sensitive to the stiffness ratio than to other parameters such as shear strength.

Barton and Choubey (1977) have suggested the following equation for calculation of shear stiffness $\left(k_{s}\right)$ from some of the same parameters that are used in the nonilnear representations of discontinuity shear strength and normal stiffness:

$$
k_{S}=\frac{100}{L} \sigma_{n} \tan \left(J R C \log _{10}\left(\frac{J C S}{\sigma_{n}}\right)+\phi_{r}\right)
$$

This equation is based on observations by Barton and Choubey that peak shear strength is reached when shear displacement has reached about one percent of the discontinuity length $(L)$ measured in the direction of silding. Discontinuity length will of course depend on block and excavation geometry. Equation 12 is used in keyblock behavior analys is in conjunction with the nonlinear normal stiffness and shear strength equations.

\section{Load and Stress Conditions}

Three different types of stresses and forces that influence keyblock stability are included in calculations of keyblock behavior. These are the stresses in situ as modified by the presence of the underground opening, the changes in the stress fieid around the opening that result from temperature changes, and the i.. $\quad \therefore$ slock itself. The block weight is a matter of rock density and the block volume calculated from the geometry of a given problem, and so witl be discussed below as part of the summation of forces 
acting on the block. Fluid pressures within the discontinuities and temperature-induced stresses are not included in this analysis, but can be added readily. Ground support forces can also be added to the force summation equations; they are not included here because they do not enter into the more fundamental problem of the behavior of an unsupported keyblock.

for three-dimensional problems, most previous investigators have assumed that the block under analysis is located in a planar excavation surface, and that the stresses are tangential to the opening (see Table 1). A generalized plane strain solution developed by Amadet (1982) is available that allows the three-dimensional stress tensor to be calculated as a function of location around a cylindrical opentig in an arbitrary in situ stress field. This solution has been modified for a three-dimensional keyblock behavior model, and is used to compute the stresses acting on a grid of points representing each block face. These initial stresses aro then adjusted for the effects of keyblock displacement.

\section{Formulation of Keyblock Stability Equations}

Evaluation of the behavior and stability of a keyblock requires that the forces affecting the block be summed into a resultant that can be evaluated for magnitude a direction. The forces included are the weight of the keyblock ?nd the normal and shear stresses numerfcally integrated over each block face that they act upon. These normal and shear stresses are a function of their location on the block surfaces, the initial stresses, keyblor.k weight, and keyblock displacement. Procedures for computing most of these quantities have been outlined above; they are now combined to formulate a 
method for stability analysis. Block welght is brought into the calculation when the stresses are summed into resulting forces; this is not strictly correct. The error that it causes is discussed below.

Only a three-dimensional approach or model will be described since a two-dimensional model represents a simpler application of the same principles. The method calculates a total resultant force in the tunnel coordinate system as a function of keyblock displacement, instead of the opposite approach of finding the displacement that results from a combination of forces. This resultant force can then be examined for a number of specified displacements (1) to see if equilibrium is reached as the block slips, and (2) to see if any excess resisting forces are avallable to provide a margin of safety against fallure for stable blocks.

To begin an analysis of keyblock behavior, the initlal (pre-displacement) stresses on the keyblock faces must be calculated. Three sets of coordinate systems are needed as listed in Table 2. The unperturbed in situ stresses that exist prior to construction are referenced at first to the global coordinate system, but are rotated into the tunnel coordinate system in which the keyblock resides using Goodman's (1980) procedures. Since the stresses are not uniformly distributed over each block face once the opening is excavated, a grid of points (ar nodes) is set up for each discontinuity face of the keyblock in order to allow numerical integration of the stresses into forces. The stresses (modified elastically by the cylindrical excavation) are calculated for the sidd points using the tunnel coordinate system. Each face has a coordinate system of its own, though, which is based on the normal to the discontinuity that creates the face and the projection of the displacement 
vector onto the face (Table 2). The stress tensor at each grid point is rotated from the tunnel coordinate system to the face coordinate system. Once these computations are complete, the initial normal stress and inttial shear stress (for zero block displacement) are avallable for each grio point.

Table 2 Coordinate Systems Used in Ihree-Dimensional Keyblock Behavior Ana lys is

\begin{tabular}{llll}
\multicolumn{1}{c}{ System } & \multicolumn{1}{c}{$+X$ axis } & $+Y$ axis & $+Z$ axis \\
Global & East & North & Vertical up \\
Tunne & $\begin{array}{l}\text { Horizontal } \\
\text { Through Springline }\end{array}$ & Tunnel Axis & $\begin{array}{l}\text { Through Back } \\
\text { Perpendicular } \\
\text { to Xand } Y\end{array}$ \\
$\begin{array}{l}\text { Keyblock } \\
\text { Face }\end{array}$ & $\begin{array}{l}\text { Transverse to } \\
\text { Projected Displacement } \\
\text { Direction in Face }\end{array}$ & Normal to Face & $\begin{array}{l}\text { Parallel to } \\
\text { Projected } \\
\text { Displacement } \\
\text { Direction }\end{array}$
\end{tabular}

NOTE: (1) One face system is used for each keyblock face that is not an excavation surface.

If nonlinear discontinuity deformation is to be accounted for, some intermediate calculations are needed. Once the face grids are set up, but before the in situ stresses are adjusted for the effects of the excavation, the normal stresses on the discontinuities are found and used with equation 10 to obtain estimates of aperture closures. These closures represent average values for each discontinuity under ambient in situ stresses, and are used in equation 8 to compute initial normal stiffnesses. The initial normal 
stiffnesses are used to set up a hyperbolic equation for normal stiffness for each discontinutty. The effects of the underground opening on the stress fleld are then calculated as mentloned above; the stresses usually increase because of the stress concentrations around the tunnel. These increases in normal stress are used with the hyperbolic equations to adjust the normal stiffness and aperture value at each grid point prior to the start of keyblock displacement. Note that each part of the calrulational grid may be at a different point on the hyperbolic curve for that discontinuity, and that even though the rock is assumed to be rigid, the discontinuity is at siightiy varying degrees of closure along its length prior to any block displacement because of the distribution of normal stresses.

The next step is to adjust the initial stresses for an increment of displacement in a specified direction. This is done in a sequence of operations: First, the displacement is resolved into its net effect on each discontinuity grid point in terms of an aperture change (normal) component and a sliding (shear) component. If the angle between the displacement vector and the discontinuity $p$ lane is $\beta$, and the face has a dilatancy angle $\left(1^{\circ}\right)$, then the amount of aperture opening $\Delta V$ that occurs with displacement $D$ is:

$$
\Delta V=D(\sin \beta-\cos \beta \tan 1)
$$

In this equation the $\sin \beta$ term represents the movement of the block away from the average discontinutty surface, while the $\cos \beta \tan 1$ term is a dilatancy effect that reduces the opening of the surface. Aperture opening is positive and closure is negative in this equation. The dilatancy angle is specified for each face for linear analyses, and is extracted from the shear strength equation (Equation 2) for nonlinear analyses. 
Simtlarly, shear slip along each average discontinuity surface is given ty:

$$
\Delta U=D \cos \beta
$$

The next operation in the :equence is to adjust the ncrmal stresses at each grid point. For the nonitinear analysis, this is done by entering the hyperbollc stiffness equations with the adjusted aperture values and calculating new normal stresses for each grid point. For a linear analysis, the initial normal stress $\left(\sigma_{n q}\right)$ for each point is modified as follows:

$$
\sigma_{n}=\sigma_{n 1}-k_{n} \Delta V
$$

With increasing keyblock displacement, the normal stiffness and normal stress follow an unloading path as the block separates from the surrounding rock. The available shear strength also drops because of its relationship to the normal stress, while the shear stresses increase unt1l they reach the level of shear strength that is mobllized. Equation 1 or 2 is therefore used with the adjusted values for normal stress to determine the available shear strength at each grid point. The shear stress at each point is then set equal to the avallable shear strength, or the shear stress is calculated from shear stiffness and displacement, whichever is less. The shear stress calculated from the initial shear stress $\tau_{i}$ and the displacement is:

$$
\tau=\tau_{i}+k_{s} \Delta U
$$

During the calculations of block geometry necessary for setting up the grids for each face, the block volume is computed and used to obtain the weight of the keyblock. Face areas are also assigned to each grid point to allow numerical integration of stresses into forces acting normal and parallel 
to each face. These forces are then rotated into the global coordinate system and summed. Under the convention of positive being upward in the tunne $z$ axis direction, the keyblock weight (W) is a negative force. If the final resultant force (F) is ortented upward, it represents an excess of shear force that must be overcome in order to pull the keyblock out of the surrounding rock mass to the specifled level of displacement. If, conversely, $F$ is negative (acting downward) it represents a force which must be resisted by support system for the block to be at equilibrium at the given displacement.

The resultant force $F$ can be normalized by dividing by weight $W$; the expression $F / W$ is a raslo of resultant force to keyblock weight. The sign of the ratio can also be switched so that a positive $F / W$ indicates a support that must be supplied for stability, while a negative FiW implies a negative support, or pullout force. Using this sign convention, the $F / W$ ratio can be related to a factor of safety (FS) by the following equation:

$$
F S=1.0-F / W
$$

It must be remembered that each $F / W$ value for a given keyblock has a specific displacement associated with it. Figure 6 plots $F / W$ against displacement (a block reaction curve) for a typlcal keyblock that might fail by falling. This convention is used because it is conceptually similar to a ground reaction curve.

Inspection of the block reaction curve of Figure 6 reveals several interesting points about the displacement behavior of a stable keyblock. As the block starts to displace, the block reaction curve (f/W ratio ys displacement) starts out above, rather than at, unity. This reflects an 
elastic unloading of the discontinuties that occurs during excavation of the opening, and indicates that a force much greater than the block weight would be needed if the block were to be shoved back into a zero displacement condition. Second, $F / W$ drops with increased displacement, and the keyblock reaches equllibrium and presumably stops moving once $F / W$ reaches zero. If additional displacement is specified or allowed, however, the curve continues down until a minimum is reached. After this the peak shear strength of the discontinuities has been exceeded at all points by the mobilized shear stresses, and the curve trends upward until $\mathrm{F} / \mathrm{W}$ equals unity, At this and larger values of displacement, the block faces have lost all shear strength and are likely to be entirely separated from the surrounding rock, and the entire block weight must be supported.

A plot of $F / W$ versus displacement for a marginaliy unstable keyblock has a form simtlar to that of Figure 6 , except that $F / W$ remains positive for all displacement values. This indicates that the block never reaches a stable condition without support. Completely unstable keyblocks present a curve that never goes below unity, while safe keyblocks cease moving at an $F / w$ ratio of zero or less (factor of safety greater than one). Figur? 7 shows typical block reaction curves for all tinree types of blocks for comparison.

PARAMETER EFFECTS ON KEYBLOCK STABILITY

Back-analysis of fleld observations of fallen and stable keyblocks (Yow, 1985) Indicates that a three-dimensional numerical model can be used to estimate keyblock stability. Back-analysis of laboratory tests of block pullout force under varlous confining pressures indicates that a 
two-dimensional numerical model can be used to estimate pullout force, which 15 simply a different way of approaching block 5 tability. Both numerical models use the same representations of discontinuity strength and deformation. and both apparently can be used to evaluate the stablilty of keyblocks if appropriate information is available or can be estimated for block geometry, in situ stresses, and discontinulty properties. The results of parametric studies that were made to examine the effects of stresses, discontinuity stiffness and shear strength, block ge'meti, and displacement on statility are described below. Some inherent limitations of the stability analysis metnods are discussed before presenting the results of the scoping calculations.

\section{Description of KeyDlocks Used for Studies}

Figure 8 shows the symmetrical two-dimensional and three-dimensional keyblocks used for most of the parametric studies. A horizonta? tunnel with a radlus of $1.8 \mathrm{~m}$ (72 inches) was modeled; the radius from the tunnel centerline to the block apex was $2.4 \mathrm{~m}$ (96 inches). Each discontinuity forming a block face dips at $60^{\circ}$ below horizontal, and joint apertures for negligible norma? stress are $0.001 \mathrm{~m}(0.04$ inches). In situ principal stresses prior to excavation of the tunnel are assumed to act vertically and, in a horizontal plane, at $45^{\circ}$ angles from the tunnel axis.

Table 3 lists in three categories the parameters that were studied for their effect on keyblock stability. In addition to the parameters listed in Table 3, a comparison was made of two-dimensional versus three-dimenstonal model results and of 71 near and nonlinear representations of discontinuity 
behavior. Block stabllity is a function of all of these parameters, but some parameters influence stabllity more strongly than do others. In the studtes below, only one parameter was varied at a time. The results were plotted on similar scales so that the relative significance of a given parameter in a design problem could be jusged from its expected variability and from the gradients of the curves plotted from the parametric studies.

All combinations of parameters that were studied used symetric blocks in the tunnel crown. This was because the stability solution is sensitive to whether or not the selected displacement direction is correct. In a design analysis several different directions of displacement would be examined in a searching sequence that is similar to the way in which a soll mechanics slope stability analysis searches for critical circles along which slope fallure would most likely occur. Use of a symmetric crown block allowed the displacement direction to be specified as vertically downward so as to find ine results of an analysis as quickly as possible.

Table 3 Parameters Examined for Effect on Keyblock Stability

$\begin{array}{lll}\text { Discontinutity Behavior } & \text { Stresses } & \text { Keyblack Geometry } \\ \text { shear strength } & \text { stress magnitude } & \text { block acuteness } \\ \text { deformation stiffness } & \begin{array}{l}\text { lateral stress } \\ \text { ratio }\end{array} & \begin{array}{l}\text { block slze (tunne } \\ \text { stze constant) }\end{array} \\ & \text { block and tunne } 1 \\ & \text { size (scale) }\end{array}$




\section{Limitations of Stability Analys is Method}

The stablitty solutions provided by the numerical models are subject to certain limitations in accuracy because of the sequence in which forces are summed. The selection of two-dimensional versus three-dimensional analysis procedures makes a difference in the results, although it is one that can be anticipated. These factors are in addition to the assumptions about geometry, stiffness, and stresses that were used in developing the equations above.

As described previously, the sequence of operations in evaluating block stablitty for a given amount of displacement is to first calculate the effect of the displacement on the stresses affecting each block face, and then sum those stresses with the block weight into a resultant force. A possible error that can arise in this sequence of calculations is the place in the procedure at which the block weight is brought into the equations. An increment of displacement is used to compute a change in normal stress and shear stress on a block face; the shear stress is then constralned by the avallable shear strength, which is a function of normal stress. A component of the block weight should ideally be included in the normal and shear stress at each grid point. In the analysis models the weight is not brought into the calculations for each displacement increment unt1l the stresses are summed at the end of that increment. This is because of the difficulty of apportioning a component of the block weight to each block face in a generalized solution procedure. For a typical two-dimensional analysis of the block shown in Figure 8a this would make a difference of less than $2 \%$ in the normal stress at fallure, and a difference of about $3 \%$ in the shear stress. Investigators do not usually know shear strength to within 3\%, for example, and so the effects of the force summation sequence are overshadowed by uncertainties of the input data. 
Another source of small errors in the analysis procedures is the iterative approach used in determining a dilation angle for calculating aperture changes in the nonlinear discontinuity behavior equations. In the linear representation the dilation angle (i) is a constant, but in the nonlinear representation the dilation angle is:

$$
1=\operatorname{JRC} \log _{10}\left(\frac{\mathrm{JCS}}{\sigma_{n}}\right)
$$

from equation 2. Since $\sigma_{n}$ is a function of aperture closure (Figure 5), and closure is partiy a function of dilatancy, the numerical models use equivalent dilatancy angles from the previous displacement increment rather than iterating to find "current" values of dilatancy angles for use in computing aperture changes. Again, this produces an error in the computed resultant force that is typically of the order of two or three percent. This is not significant for most stability calculations for parametric studies, particularly since the error is systematic.

Recall that $F / W$ is the ratio of resultant support force to block weight; the support force is the force needed to hold the block at equilibrium at the specified level of displacement. Positive $F / W$ ratios thus indicate that an actual supporting force must be applied for the block to be at equilibrium at that displacement, while a negative $F / H$ indicases a pullout force that must be applied to pull the block out to that displacement. Recalling equation 17, if $F / W>0$ then the factor of safety is less than unity, while if $F / W<0$ the factor of safety is greater than unity. 
An unsupported block in a constant stress fie?d could be expected to displace under its own weight until either it falls completely or it reaches a condition of equilibrium at a displacement where $F / W=0$. Negative $F / W$ values therefore indicate a reserve of stabllizing shear resistance against block fallure that can be moblifized by increasing displacements. This presumes that discontinuity properties and loading conditions are constant with time. If displacement continues past the minimum $F / W$ point, the peak resisting force is surpassed, and the block falls catastrophically as soon as $\mathrm{F} / \mathrm{W}$ becomes posittve. If the block is supported, displacement can continue unt? the entire block weight is carrled by the support $(F / H=1)$ or equilibrlum is reached at an intermediate point.

The selection of two-dimenstional versus three-dimensional analysis procedures makes a decided difference in the stability solutions obtained. Figure 9 compares block reaction curves for three-dimensional and two-dimensional blocks of the form shown in Figure 8 . All discontinuties dip at $60^{\circ}$ below horizontal, and the problems are equivalent in terms of stiffness, initial stress, and shear strength parameters. Hevertheless, it can be seen that the 2D approach underestimates the stability of the block in comparison to the 30 approach. This is apparently caused by the block confinement and additional strength avallable in the geometry of the 30 approach. Most of these parametric studies were made with 30 analyses secause they are more realistic than 20 calculations.

\section{Keyblock Displacement}

As the keyblock of Figure 8a displaces from the position that it occupled prior to opening of the excavation, the stresses acting on each block face 
change continually until the block either falls or becomes stable. Figure 10 8 shows block reaction curves for typical nonlinear and linear analyses of geometrically identical blocks. It is difficult to estimate properties for linear stiffness and shaar strength to perfectly match the results of a nonlinear analysis, so the minimum $F / W$ values seen in the two curves do not quite agree.

Two important results can be seen in the general shapes of these curves, however. First, the block reaction curve descends to a minimum F/N ratio somewhat more quickly for the linear behavior. In other words, the linear approximation results in a faster "unloading" of the block towards equilibrium than does the nonlinear model. Second, and more importantly, once the minimum $F / W$ has been passed the linear model indicates a raptd upward trend to where $F / W$ becomes positive and the block falls. The nonlinear model shows a more gradual $\mathrm{rise}$ in $\mathrm{F} / \mathrm{H}$ once the minimum is surpassed, indicating greater possible keyblock displacement before fallure occurs. The nonlinear model is more accurate and is used for most of these parametric studies, but the linear approximation is more conservative for design use if the assumed linear stiffness values are good estimates.

In genera1, properties used in either type of analysis affect the block reaction curve in two ways. The shear strength values limit the shear stress on the block faces and thus control the minimum $F / W$ value that can be obtained with block displacement, other things being equal. The stiffness properties in turn control the stress changes that occur with displacement, and hence determine the magnitude of displacement that is necessary to get to the 
minimum $F / W$, other things again being equal. In other wordṣ, the shear strength affects the lower limit of the curve, while the stiffness affects the magnitude of permissible block displacement.

\section{Dtscontinuity Shear Strength}

The shear strength of each discontinuity making up the keyblock contains a dilatancy component and a friction component. Friction is represented by an angle $\phi_{r}$. While dilatancy is represented by equation 18 for nonlinear behavior. These quantitles define the shear strength that is avallable under a given normal stress using equation 2. Figure 11 shows the ways in which changes in these three parameters affect keyblock stablitty.

In Figure 11a, the minimum $F / W$ ratio that can be achieved for the pyramijal block of Figure $8 a$ is plotted as a function of joint roughness coeificient (JRC). This plot assumes a hydrostatic stress field prior to excavation, with a stress magnitude of $3.45 \mathrm{MPa}(500$ psi) in compression. Joint compressive strength (JCS) is $20.69 \mathrm{MPa}\left(3000 \mathrm{ps} 1\right.$ ) and $\phi_{r}$ is $25^{\circ}$. The nonlinear curve indicates that block stablitty is strongly dependent on dilatancy; this becomes more evident mathematically if equation 18 is rearranged slightiy so that the exponential effect of JRC can be seen:

$$
1=\log _{10}\left(\left(\frac{J C S}{\sigma_{n}}\right)\right. \text { JRC, }
$$


Increases in JRC then imply that the discontinuity surface is rougher. This in turn makes the avallable shear strength larger, and also increases the shear stiffness.

Figure 1lb shows how the minimum $F / W$ is affected by another variable in the nonlinear formulation for dllatancy. JRC is held at 4 in this case, and $\phi_{r}=25^{\circ}$. F/H ratio is plotted as a function of JCS, and the plot shows that block stability increases as the joint compressive strength increases, a1though the effect is not as strong as that of JRC. JCS reflects the strength of the asperities that make the discontinuity dilatant; a higher JCS value implies that fewer asperities fall during shear and that correspondingly more must be overridden. Increases in JRC or JCS thus increase the shear strength and slow the decrease in normal stress as the keyblock displaces.

Finally, Figure 11c plots the change in minimum $F / W$ ratio as a function of $\Phi_{r}$. As expected, increased residual friction makes the keyblock more stable. However, the trend is not quite as pronounced as that of JRC because $\Phi_{r}$ affects only the avallable shear strength while dilatancy affects both shear strength and the changes in normal stress brought about by aperture opening or closure.

\section{Discontinuity Stiffness}

It was shown that discontinulty normal stiffness is related to the initial aperture of the fracture under negligfble normal load, and to the given normal stress acting on the fracture in situ. Converseiy, the stiffness must affect the changes in stress that are generated by block displacement. Figure 12 
shows the variation of minimum $F / H$ ratio with a range of initial normal stiffnesses. Block stability is seen to decrease as normal stiffness increases. This is berause the normal stresses decrease more quickly on stiffer discontinutties that experience a given increment of keyblock displacement. The drop in normal stress brings down the avallable shear strength before the shear stresses can became large enough to support the block. Although this effect is present, it does not appear to be as pronounced as the shear strength effects on keyblock stablilty discussed above.

\section{Stresses and Loads}

Aside fron discontinuity shear strength, the most critical condition affecting the stablitity of a given keyblock is the stress environment in which it is located. This cannot be studied by simply putting different stress values into the model and looking at the results because of the effect of normal stiffness variations in situ. Normal stiffness is a function of normal stress and can be expected to increase as stress magnitudes increase. Conceptually, this should make a rock mass stiffer with depth. Discontinuity stiffnesses were therefore adjusted for stress magnitude using the hyperbolic equations for single fractures under normal foading.

Different $E_{m}$ values corresponding to different levels of confining stress were used in the 30 block behavior model to represent overall stiffness changes so that block stability could be examined for the effects of in situ stress magnitude. Figure 13 plots the change in minimum $\mathrm{F} / \mathrm{H}$ ratio that occurs with stress magnitudes varying from $6.90 \mathrm{MPa}(1000 \mathrm{ps} 1)$ to $0.03 \mathrm{MPa}$ (5 psi), with othar parameters (including lateral stress ratio) heid constant at 0.5 . 
The trend is for the block to become less stable as the initial confining stresses decrease, and the trend accelerates as the stress magnitudes become very small.

Figure 14 shows the changes in ininimum $F / W$ ratio that result from differing lateral stress ratios at a constant vertical stress of $3.45 \mathrm{MPa}$ (500 ps1). The lateral stresses before excavation are assumed to be equal in magnitude and to act in a horizontal plane. Stability can be seen to decrease as lateral stress ratio decreases; again the trend accelerates as the lateral stress ratio goes below about one-half. Simtiar calculations were made for horizontal stress antsotropy, with average horlzontal stresses being kept constant. Since all four block faces have identical strength and stiffness and the problem geometry was symetric, the minimum $F / W$ ratios were not affected.

\section{Block Geometry}

So far the parametric studies have involved a keyblock having the geometry shown in figure 8 . The tunnel radius, block size, and discontinuity orientations have been constant while properties such as strength and stiffness have been varied. The effects of block geometry on $F / H$ ratio are now examined by varying the geometry of the pyramidal block while holding strengths, stiffnesses, and the in situ stress field constant.

Figure 15 shows the effect of keyblock narrowness or slenderness (expressed in terms of included apex angles) on block stability. The radius of the tunnel and the hefght of the block are constant, and the dips of the 
discontinuities below horizontal were varled from their values of $60^{\circ}$ used in the preceding calculations. The $60^{\circ}$ dips resulted in an included angle of $60^{\circ}$ at the bfock apex between opposite block faces. Block slenderness can be seen to have an effect similar in significance to that of changing the discontinuity shear strength. The minimum $F / W$ ratio becomes more negative (more stable) as the block becomes narrower and becomes more positive [less stable; as it becomes broader. This reflects the increased confinement of the block and corresponding increased ability to mobilize shear strength.

Figure 16 shows the effect of keyblock size on $F / W$ ratio. In this case the block height was varied while the discontinuity dips and the tunnel radius were constant. Larger blocks are apparently less stable than smaller blocks for two reasons: First, since ine block behavior model does not provide for a stress-relieved (damaged) zone of reduced stiffness around the excavation perimeter, smaller blocks are subjected to larger average confining stresses (tangent to the opening) than are larger blocks. Second, and speaking in general terms, the weight of a block increases roughly with the cube of the block height, while the surface area increases in approximate proportion to the square of the height. Since the weight is what moves a block towards fallure, and the restraining forces are generated by stresses acting on the block surface area, large keyblocks should be (and are) less stable than small ones.

Figure 17 shows how keyblock stability is expected to change as the scale of a problem changes. In these calculations the tunnel radius was varled but the ratio of block height to tunnel radius was kept constant, as were the other parameters. The observed decrease in block stabllity with increased 
scale seems to bear out the second reason for size effects outlined in the previous paragraph. The block faces are, in this set of calculations, all subjected to the same inttial stress distributions regardless of size because of the form of the elastic stress solution.

CONCLUSIONS AND APPLICATIONS

Procedures have been formulated for analyzing the combinations of forces that define keyblock stability as a function of displacement. These procedures supersede previous techniques in two ways: arbitrary, fully three-dimenstonal in situ stress flelds and nonlinear discontinutty deformation behavior can both now be properly treated ' $n$ an analysis of block stabllity. These procedures can define a reaction curve for block behavior which describes how stablitty and support requirements change with block displacement.

Table 4 gives a qualitative assessment of the relative significance of various parameters in terms of their influence on the stability of a keyblock in an underground opening. These assessments were developed from the sensitivity studies, and give a preitiminary indication of the importance of each parameter. Following sec ions amplify some aspects of these parameter influences that may not have been obvious.

The sensitivity studies show that stability of a keyblock in an underground excavation is influenced by the stress magnitudes and lateral stress ratios, among other things. Figu.e 13 tllustrated how varlations in magnitude of vertical stress affect stability with constant lateral stress 
Table 4 Relative Influence of Parameters (1) Affecting Stability of Keyblock in Crown of Tunne 1

\author{
Parameter (1) \\ discontinuity shear strength \\ discontinutty stiffness \\ in situ stress magnitude \\ lateral stress ratto
}

block s lenderness (3)

block size with respect to constant excavation size

block and excavation size;

dimenstons kept in same proportion
Relative Influence on Stability

strong

weak (2)

strong

strong influence at low stress magnitudes; weak influence otherwise

strong

moderate

moderate

NOTES: (1) The analyses did not include dynamic loads, flutd pressures in the discontinuities, or creep or plasticity effects.

(2) Stiffness affects keyblock displacement much more strongly than it does stability.

(3) Block slenderness is the smallest included angle between opposite block faces at the apex.

ratio, and Figure 14 plotted changes in stability caused by changes of lateral stress ratio with constant vertical stress magnitude. In each case, a transition from stable to unstable block behavior is seen where the minimum $F / W$ ratio (support force ratio) goes from negative to positive. At $F / W=0$ the block is marginally at equilibrium without any excess forces resisting failure.

Simtlar analyses can be done for many combinations of vertical stress magnitude and lateral stress ratio to determine what stress conditions allow a block to be stable and what conditions lead to fallure. Since stability is 
also heavily influenced by discontinuity shear strength, this type of calculation was run for two blocks having different shear strengths to see if strength changes would make a qualitative difference in the stress effects. Figure 18 plots the combinations of vertical stress magnitude and lateral stress ratio necessary for these two blocks to each be at equilibrium with an F/W ratio of zero.

The curves plotted in Figure 18 for pyramidal blocks laving the two different discontinuity shear strengths are qualitatively the same. A block is stable at relatively low lateral stress ratios if the vertical stress magnitude is large enough. At lower stress magnitudes a larger lateral stress ratio is needed for stability to be attainable, and the effect accelerates as the vertical stress magnitude becomes very small. If vertical stress is converted to excavation depth by dividing by the untt weight of the overburden, the curves agree with sbservations of tunnel stabijity in blocky ground. At shallow depths block instabllity is a problem, but at greater depths the larger in situ stresses make the opening more stable, until stresses are high enough to induce fallure of lntact rock.

Curves. simtlar to those of figure 18 can be constructed for other combinations of block geometry, shear strength, and in situ stress, but the general trends w11l be the same. These trends rationally support the intuition and experience of excavation designers. As an aside, most previous investigators (e.g., Crawford, 1982, and Crawford and Bray, 1983) have examined keyblock behavior only at relatively low horizontal stress magnitudes with zero or negligible vertical stress. These analyses would plot in the upper right-hand corner of Figure 18. 
The relationship of block geometry to keyblock stability has been considered for a selection of two-dimensional cases by Cording and Mahar (1974) and in a much more generalized three-dimensional sense by Goodman and Shi (1985). The sensitivity studies abova examined the geometric effects of block slenderness, size, and scale for the stability of a simple pyramidal keyblock. Block slenderness can be considered in terms of the angle between opposite block faces where they intersect at the apex, size refers to the block height and volume with respect to a constant excavation size, and scale refers to the size of a block and excavation when the dimensions of the two are maintained in the same proportions.

Increases in size and scale result in a decrease of keyblock stability, other things being equal. This implies that a design for an underground opening should consider first the maximum keyblock size llowed by the excavation dimensions. However, block slenderness has a more pronounced effect on stablitity than does elther size or scale. Basically, if the smallest included apex angle between two opposite faces is larger than the sum of the friction angles and dilatancy angles of the two faces, the block will fall immediately upon excavation of the opening. If the incluojed apex angle is smaller than the sum of the friction and dilatancy angles, the keyblock is potentially stable, but an analysis should be perfurmed as a check on its behavior. If the block is extremely narrow, though, it may be assumed as stable unless exceptional circumstances such as extremely low in situ stresses preva11. Consideration of block narrowness and discontinuity shear strength must include uncertainties in the data. A $5^{\circ}$ error in block face orientation, for example, can potentially affect calculated block stablitity in a way that is similar to a $5^{\circ}$ error in friction angle. 
The relationship between keyblock stability and the stresses around an underground excavation suggests that construction sequences or techniques that affect the stress fleld can also affect block stablity. Examples of this can be found in the changing pattern of stresses behind an advancing excavation face, and in the way that excavation technique can affect the rock mass.

As an excavation advances, the tunnel behind the advancing face deforms to a position of equilibrium with any support system that is installed le.g.. Panet and Guenot, 1982). Depending on the initial in situ stress conditions, the circumferential compressive stresses (hoop stresses) around the tunnel perimeter may increase behind the advancing face to reach static conditions as the rock around the tunnel deforms elastlcally. Conceptually then, a keyblock In the perimeter of a cylindrical tunnel would experience tts lowest confining stresses directly behind the advancing face. A potentially unstable block in the crown would displace into the excavation either until it failed or unt 1 its $\mathrm{F} / \mathrm{W}$ ratio reached zero. As the working face moved onward, any increase in hoop stresses around the tunne? would increase the confinement of the block and thus drive the $F / W$ ratio to a negative value, indicating an excess of forces resisting fallure. If other factors (such as loss of strength with time) do not subsequently affect the stability of the block, the most critical time in the deformation history of the block may be when it has inttially been released by the advancing excavation face.

Excavation technique can also affect keyblock stability, even if dynamic Toads from biast effects are not involved. Deere (1981) and Hattrup (1981) have both described situations where rock blocks have been dislodged behind the advancing cutterhead of a tunnel boring machine (TBM). The force applied 
to thrust the cutterhead of a TBM forward is usually provided by hydraulic cylinders acting against shoes or pads that contact the tunne 1 perimeter. These jads typically are pushed radially outward with stresses up to several hundred pounds per square inch, and must affect the stress field around the tunnel. This perturbance, even though temporary, may aggravate the problems with block stabllity by reducing confining stresses enough to allow blocks to fall.

Most of the preceding discussion has been directed towards evaluating keyblack stabllity. However, keyblock displacement can be important even if fallure does not occur. It was shown that block displacement increases the shear stresses along the block faces until either the avallable shear strength is exceeded at all points and the block falls, or enough stress has been mobilized to support the block. Two other phenomena occur simultaneously though, as the keyblock displaces: the normal stress and the normal stiffness on each discontinuity both decrease, and each discontinuity opens. The discontinutty opening may be either sight, because of shear deformation and dilatancy, or somewhat larger, due to a comblnation of shear deformation, dilatancy, and normal deformation. 8lock movement thus produces a local zone of increased fermeability (caused by increased average discontinuity aperture) and reduced stiffness (caused by decreased discontinulty norma 1 stiffness) in the perimeter of the underground opening. Both phenomena have been observed In the fleid, and each can be important. even if block fallure is avoided.

\section{ACKNOHLEDGMENT}

This effort was funded in the Lawrence Livermore Mational Laboratory (LLNL) Nuclear Waste Management Group as part of the U.S. Department of Energy's Nevada Nuclear Waste Storage Investigations Project. 


\section{REFERENCES}

Amade1, B. (1982): The Influence of Rock Anisotropy on Measurement of Stresses

In Situ, PhD Dissertation, University of California, Berkeley.

Bandis, S. C.; A. C. Lumsden, and N. R. Barton (1983): Fundamentals of Rock Joint Deformation, International Journal of Rock Mechanics and Mining Sclences \& Geomechanics Abstracts, 20, 249-268.

8arton, N. and V. Choubey (1977): The Shear Strength of Rock Joints in Theory and Practice, Rock Mechanics, 10, 1-54.

Belytschko, T., M. Plesha, and C. H. Dowding (1983): A Computer Method for the Stability Analysis of Jointed Rock Masses. Proceedings of International Conference, Constitutive Laws for Engineering Materials, Tucson, AZ, 333-339.

Benson, R. P., R. J. Conton, A. H. Merritt, P. Jol1-Coeur, and D. U. Deere (1971): Rock Mechanics at Churchill Fal1s, Proceedings of the ASCE Sympostum on Underground Rock Chambers, Pheonix, Ax, 407-486.

Cording, E. J., A. J. Hendron, Jr., and D. U. Deere (1971): Rock Engineering for Underground Caverns, Proceedings of the ASCE Sympostum on Underground Rock Chambers, Phoen1x, AZ, 567-600.

Cording, E. J. and J. W. Mahar (1974): The Effects of Matural Geologic Discontinuities on Behavior of Rock in Tunnels. Proceedings of the 1974 Rapid Excavation and Tunneling Conference. San Francisco, CA, 1, 107-138. 
Coric, S. (1979): Stability Analysis of Underground Cavities in Fissured Rock Masses, Proceedings of the 4th International Congress on Rock Mechanics, Montreux, Swttzer land, $\underline{3}, 475-479$.

Crawford, A. M. (1982): Rock Wedge Stability, Proceedings of the 23rd U.S. Symposium on Rock Mechanics. Berkeley, CA, 1057-1064.

Crawford, A. M. and J. W. Bray (1983): Influence of the In Situ Stress Field and Joint St1ffness on Rock Hedge Stabillty in Underground Openings, Canadian Geotechnical Journal, 20, 276-287.

Croney, P., T. F. Legge, and A. Dhalla (1978): Location of Block Release Mechanisms in Tunnels from Geologic Data and the Design of Associated Support, Proceedings of the Conference on Computer Methods in Tunnel Design, London, U.K., 97-119.

Daemen, J. J. K. (1983): S1ip Zones for 01scontinulties Parallel to Circular Tunnels or Shafts, International Journal of Rock Mechanics and Mining Sciences \& Geomechanics Abstracts, 20, 135-148.

Deere, D. U. (1981): Adverse Geology and TBM Tunneling Prob lems, Proceedings of the 1987 Rapid Excavation and Tunneling Conference, San Francisco, CA, 1. 574-586.

Goodman, R. E. (1976): Methods of Geological Engineer ing in Discontinuous Rocks. Hest Publishing Company, St. Paul, MN. 
Goodman, R. E. (1980): Introduction to Rock Mechanics, John Wiley \& Sons, New York, NY.

Goodman, R. E. and G. Shi (1981): Geology and Rock Slope Stability Application of the Keyblock Concept for Rock Slopes, Proceedings of the 3rd International Conference on Stability in Surface Mining, Vancouver, Canada, 347-373.

Goodman, R. E. and G. Sht (1985): Block Theory and Its Application to Rock Engineering, Prentice Hall, Englewood Cliffs, MJ.

Goojman, R. E., G. Sh1, and H. Boyle (1982): Calculation of Support for Hard, Jotnted Rock using the Keyblock Principle, Proceedings of the 23rd U.S. Symposium on Rock Mechanizs, Berkeley, CA, 883-898.

Hattrup, J. S. (1981): Development of Tunne1 Boring Machtne Systems for Ground Control, Proceedings of the 1981 Rapid Excavation and Tunneling Conference, San Franctsco, CA, 1, 587-598.

Heuze, F. E. (1980): Scale Effects in the Determination of Rock Mass Strength and Deformability, Rock Mechanics, 12, 167-192.

Heuze, F. E., W. C. Patrick, T. R. Butkcivich, J. C. Peterson, R. V. de la Cruz, and C. F. Voss (1982): Rock Mechanics Studies of Mining in the Climax Granite, International Journal of Rock Mechanics and Mining Sclences \& Geomechanics Abstracts, 19, 167-183. 
Hoek, E. (1977): Structurally Controlled Instability in Underground Excavations, Proceedings of the 18th U.S. Symposium on Rock Mechanics. Keystone, CO, 5A6-1 through 5A6-5.

Hoek, E. and E. T. Brown (1980): Underground Excavations in Rock, The Institution of Mining and Metallurgy, London, U.K.

Obert, L. and W. I. Duval1 (1967): Rock Mechantcs and the Design of Structures In Rock, John Wtley Sons, Hew York, NY.

Panet, M. and A. Guenot (1982): Analysis of Convergence Behind the face of a Tunne1, Proceedings of the 3rd International Symposium: Tunneling '82, Institution of Mining \& Metallurgy, London, U.K., 197-204.

Shi, G. and R. E. Goudman (1981): A New Concept for Support of Underground and Surface Excavations in Discontinuous Rocks Based on a Keystone Principle, Proceedings of the 22nd U.S. Symposium on Rock Mechanics, Boston, MA, $290-296$.

Warburton, P. M. (1981): Vector Stability Analysts of an Arbitrary Polyhedral Rock Block with any Number of Free Faces, International Journal of Rock Mechantes and Mining Sclences \& Geomechantes Abstracts, 18, 415-427.

Yow, J. L.. Jr. (1985): Fleld Investigation of Keyblock Stability, Lawrence Livermore National Laboratory Report UCRL 53632. 
Zhifa, Y. (1983): Application of the Method of Projection on Coordinate Planes to Designing an Underground Opening within Discontinuous Rock Mass, Proceedings of Internationa1 Symposium on Engirsering Geology and Underground Construction, Lisbon, Portuga 1, I.15-I.24.

Zhu, J. and Zhizhong Xiao (1982): The Method of Evaluation for the Stability of Karst Caverns, Rock Mechanics: Caverns and Pressure Shafts, 1, 519-528. 


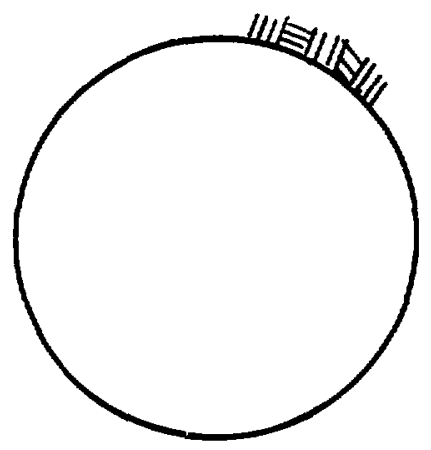

Figure 1a Tunnel in continuous rock mass.

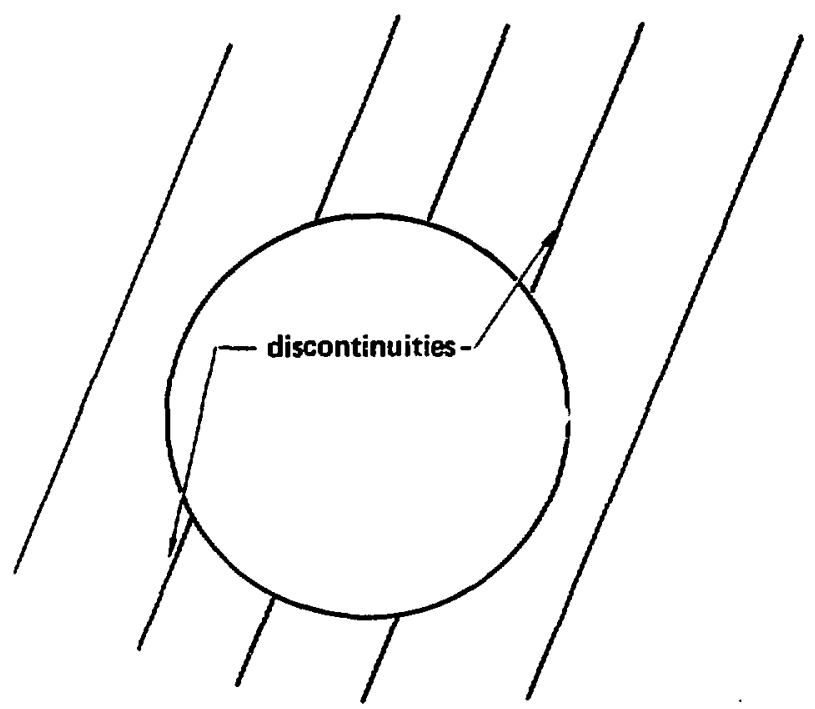

Figure 1b Tunnel in rock mass containing a single ubiquitous discontinuity set. 


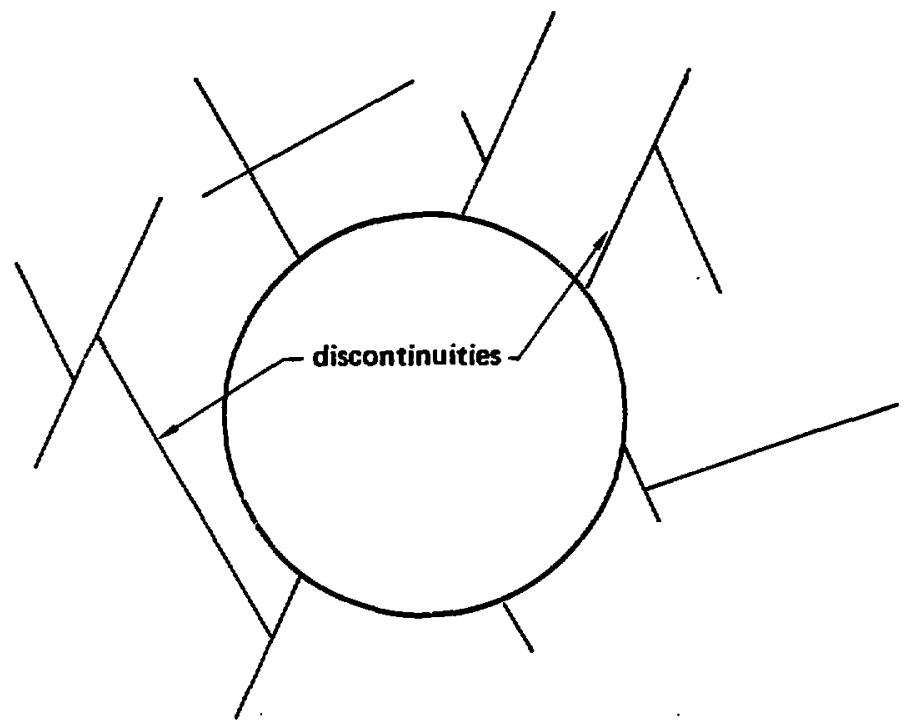

Figure ic Tunnel in rock mass with several discrete discontinuities.

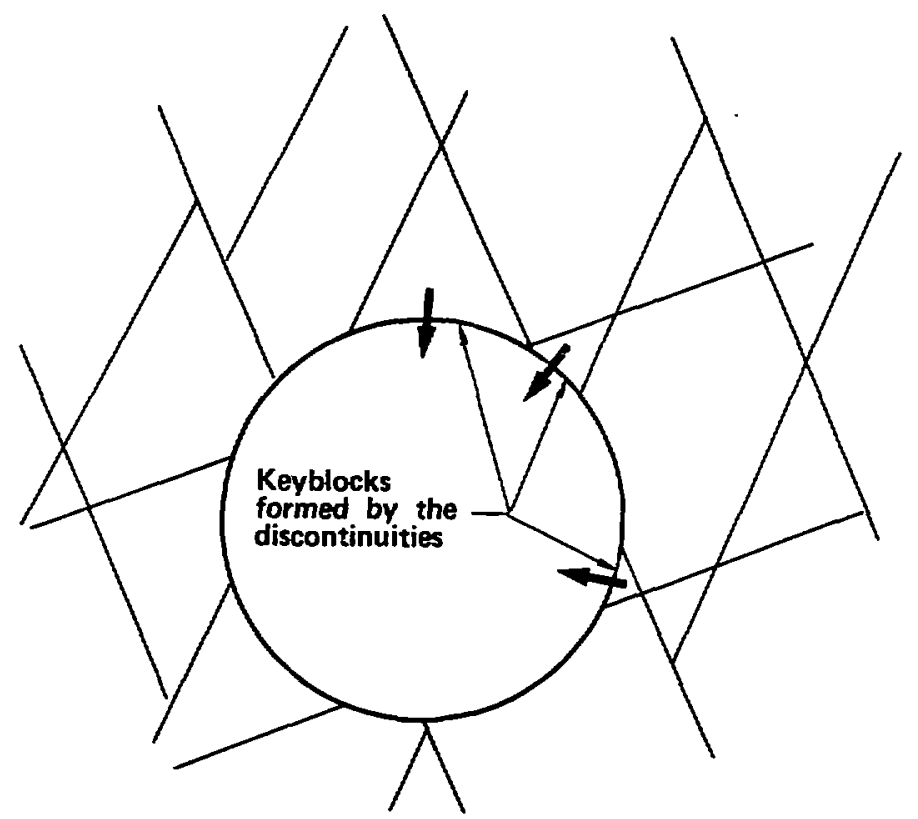

Figure id Tunnel in rock mass with discontinuities intersecting to form keyblocks. 


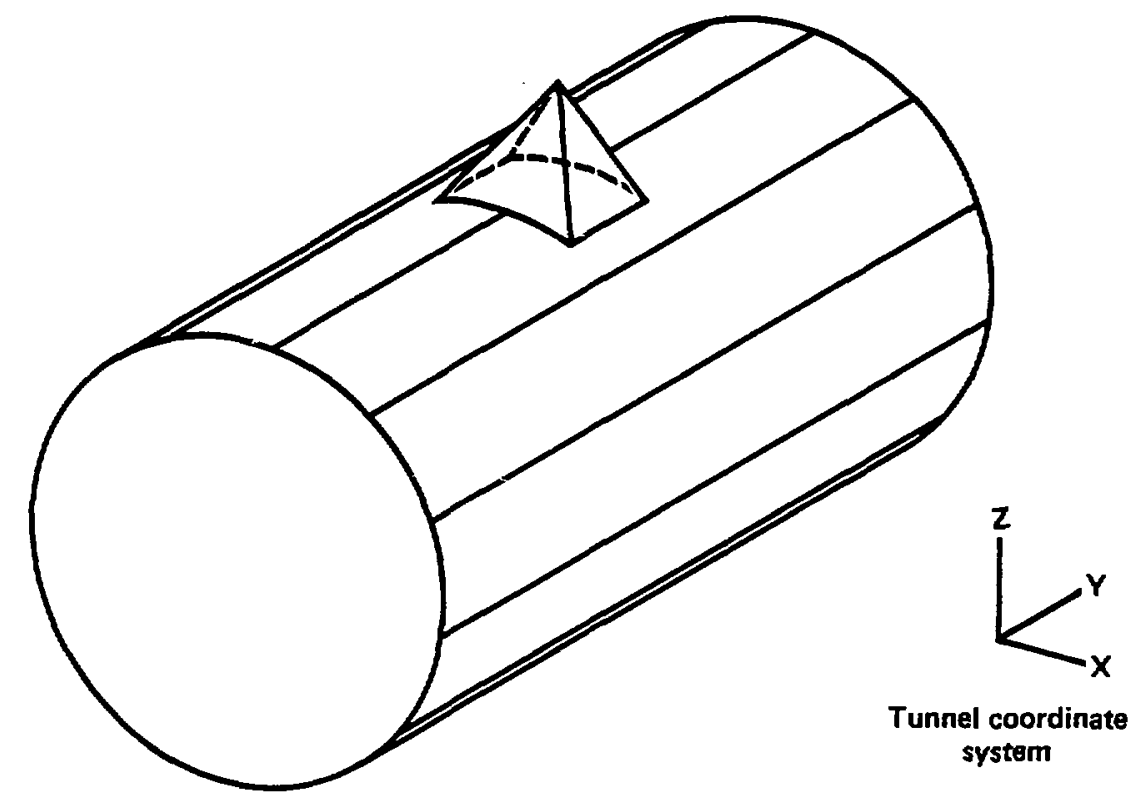

Figure 2 Typical geometry of pyramidal keyblock. 

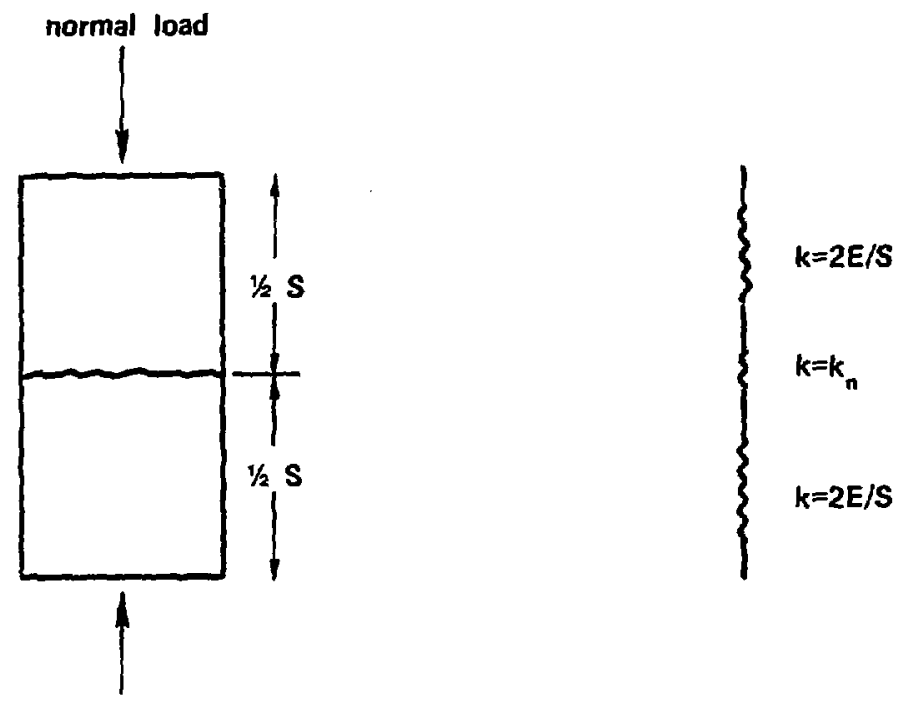

rock specimen with a discontinuity

spring system

Figure 3 Representation of rock mass by system of springs of varying stiffness. The discontinuities in the rock mass are assumed to have spacing $S$ and normal stiffness $k_{n}$. The intact rock has an elastic modulus $E$. 


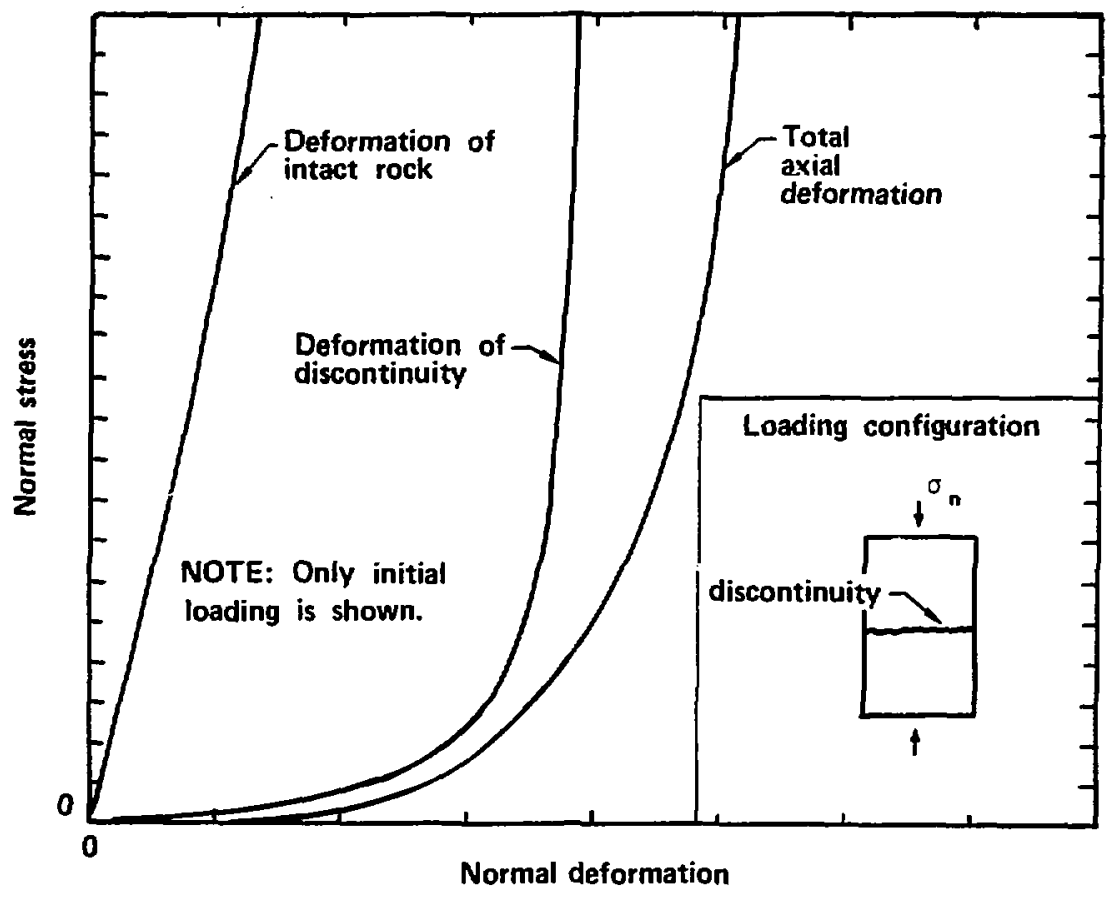

Figure 4 Typical form of normal deformations resulting from axial loading of a rock sample containing a discontinuity. 


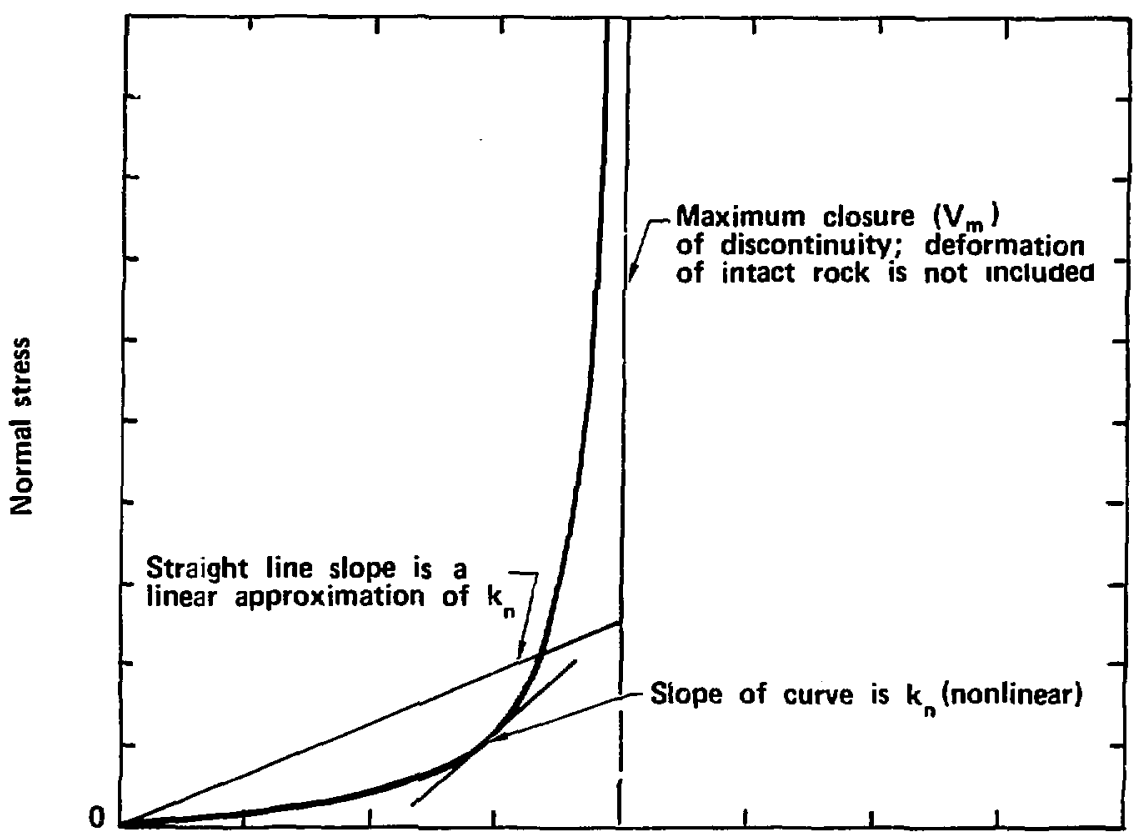

Normal deformation

Figure 5 Linear and nonlinear representations of discontinuity normal stiffness. 


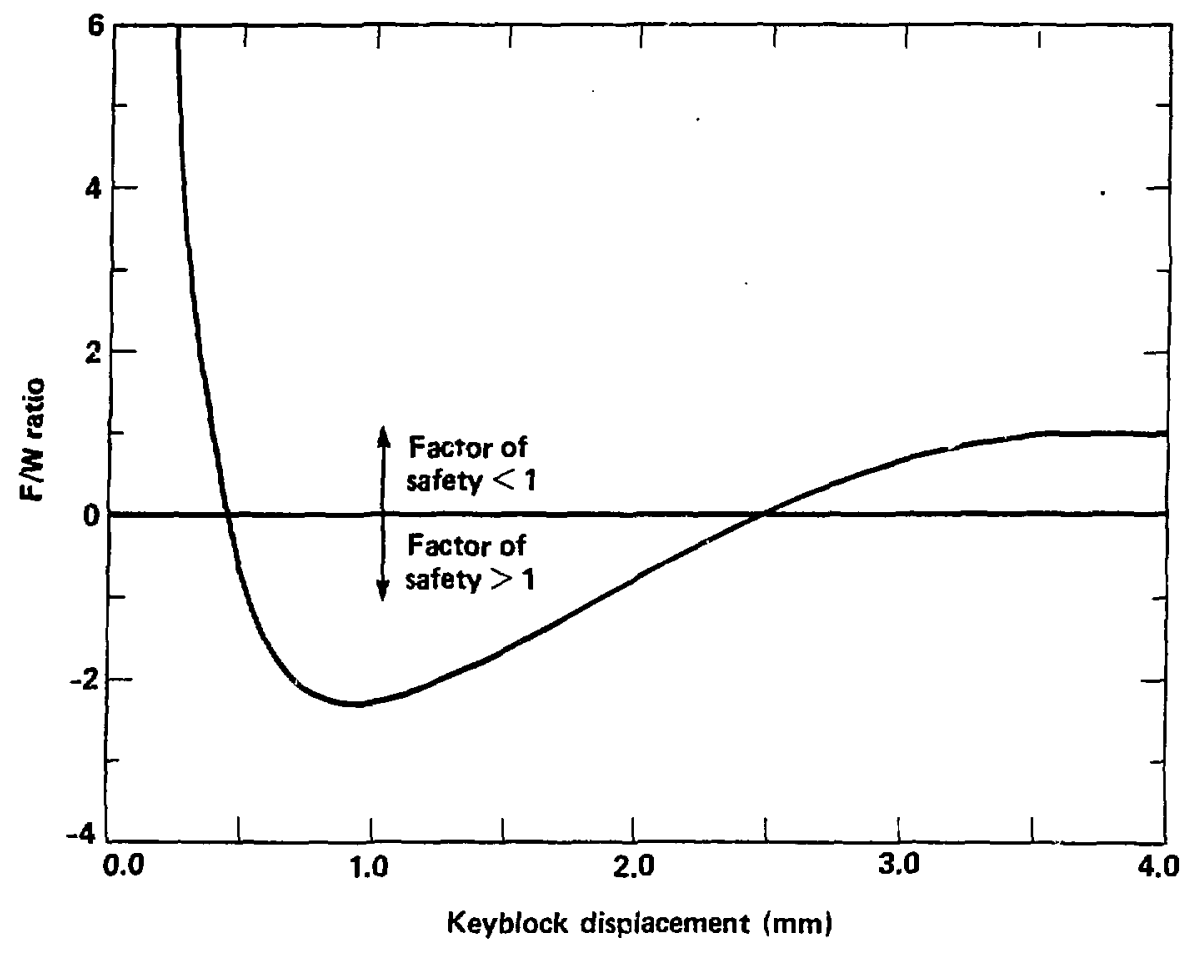

Figure $6 \mathrm{~F} / \mathrm{W}$ ratio as function of displacement (block reaction curve) for falling keyblock. 


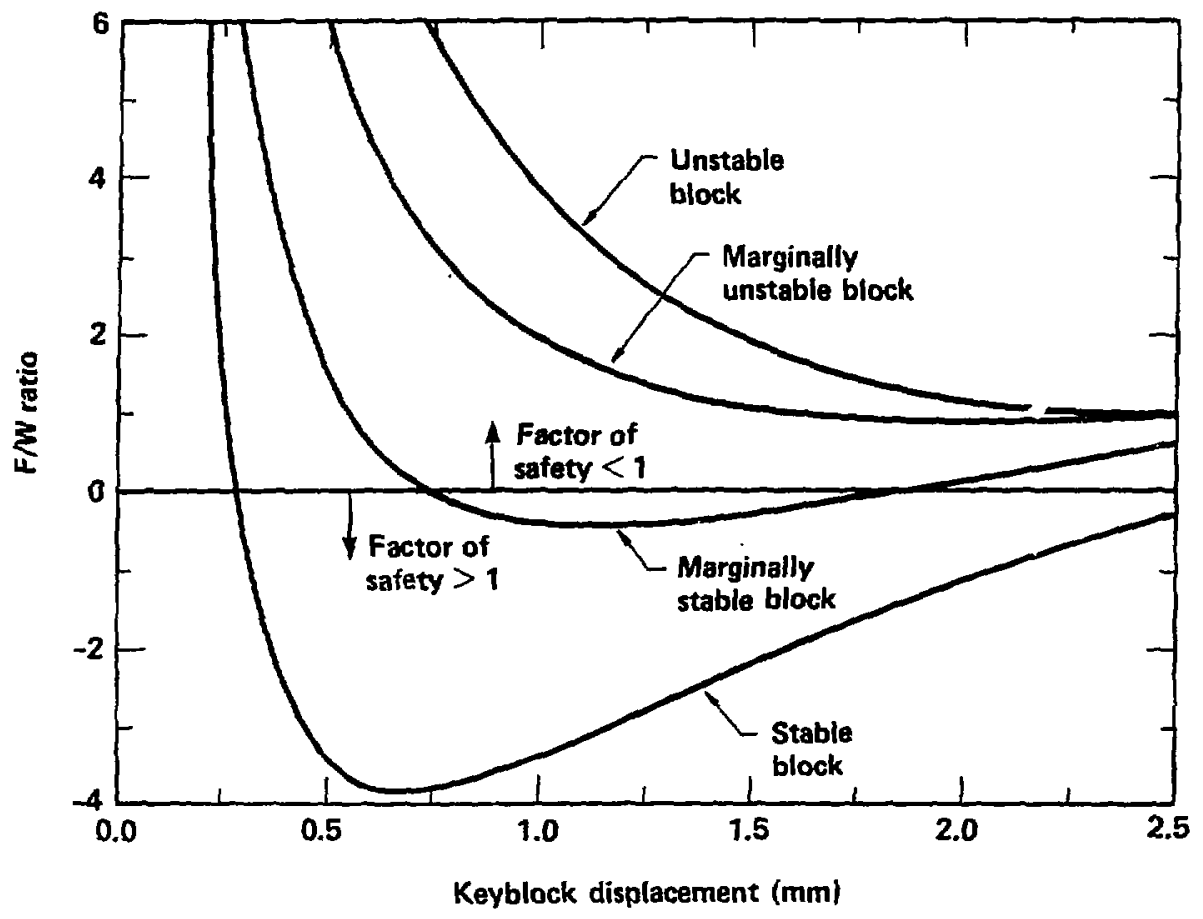

Figure 7 Block reaction curyes for stable, marginal and unstable falling keyblocks. 


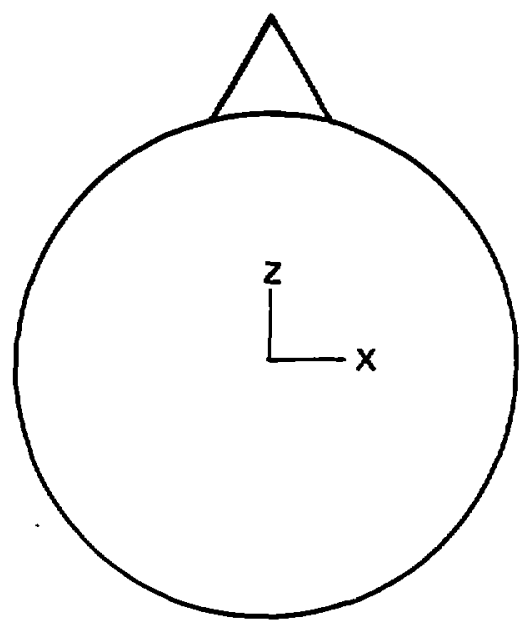

Figure 8a Typical symmetric keyblock used for two-dimensional studies. 


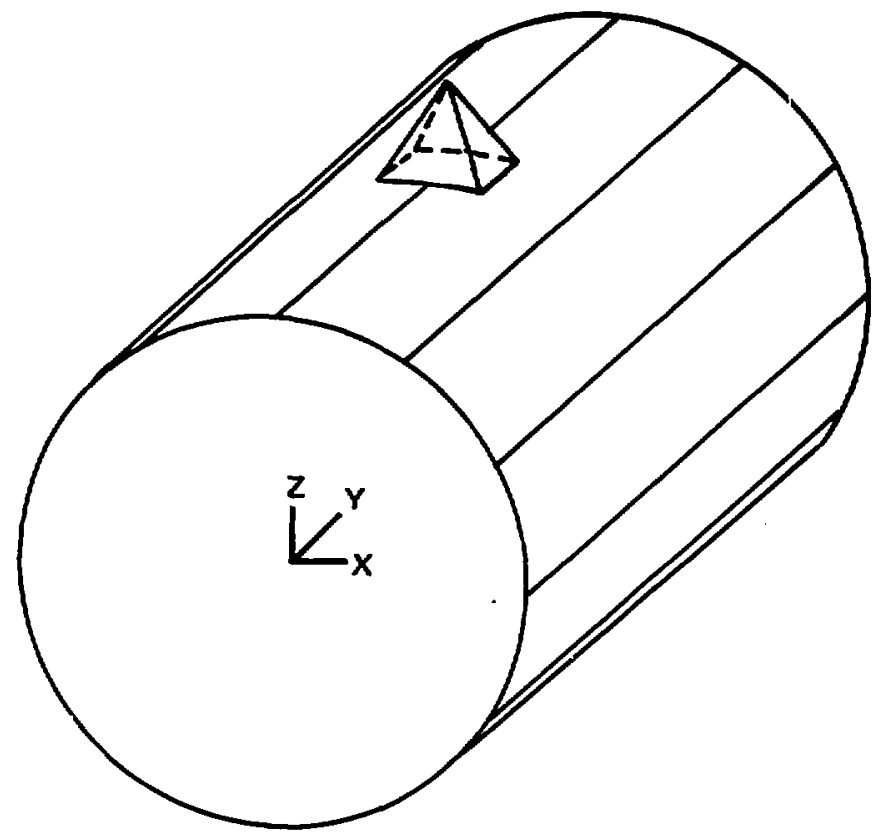

Figure 8b Typical symmetric keyblock used for three-dimensional studies. 


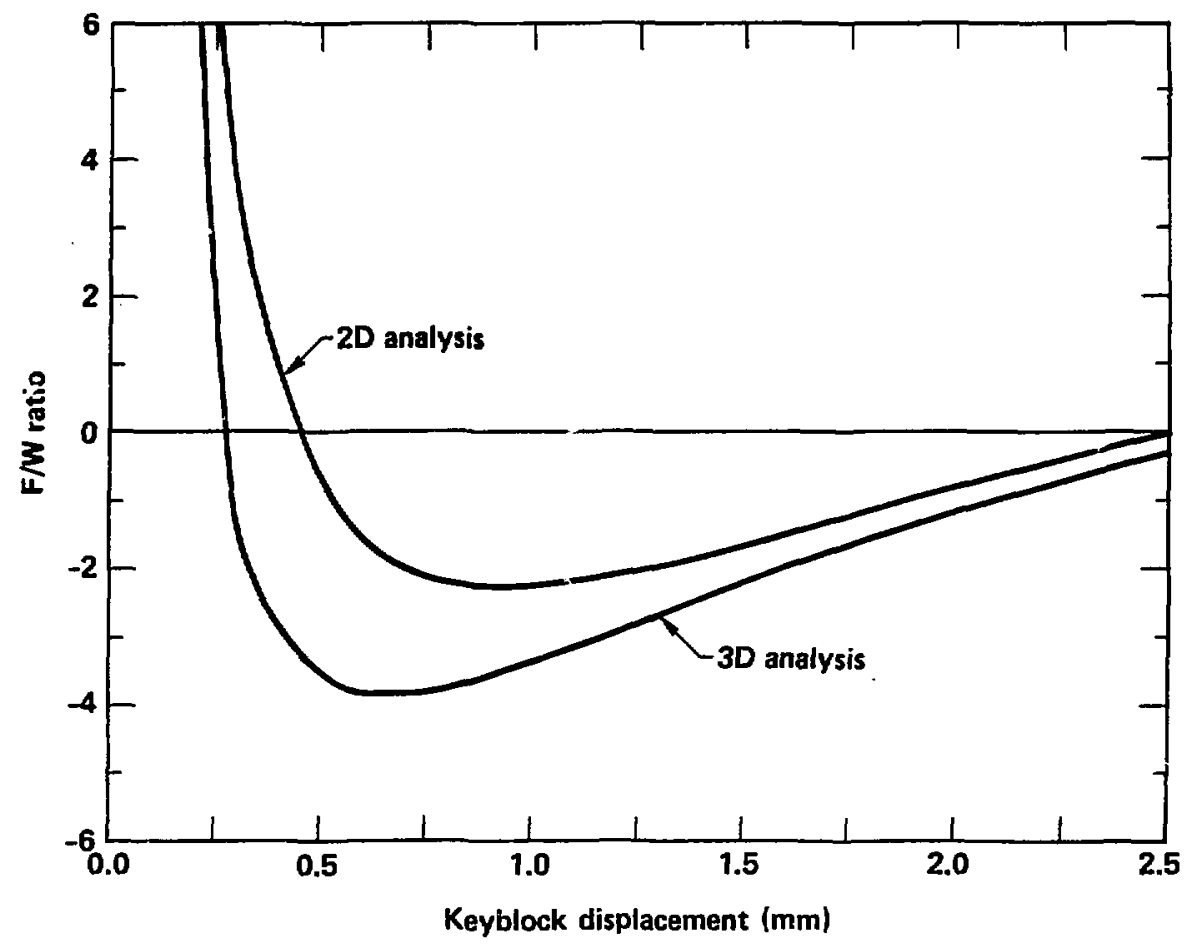

Figure 9 Biock reaction curves for 2D and 3D analyses. Other parameters same in both cases. 


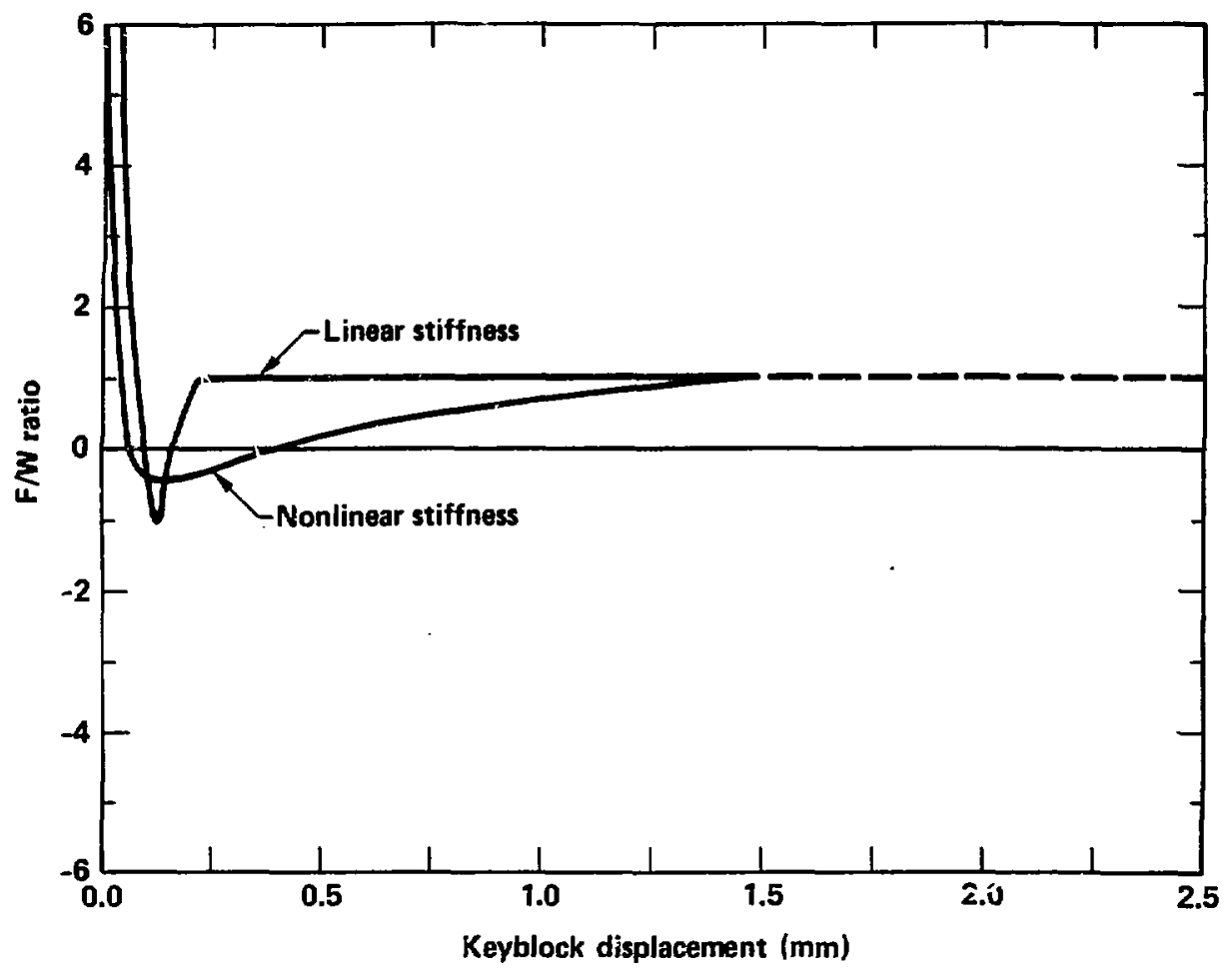

Figure 10 Block reaction curves of 3D keyblock for linear and nonlinear discontinuity models. 


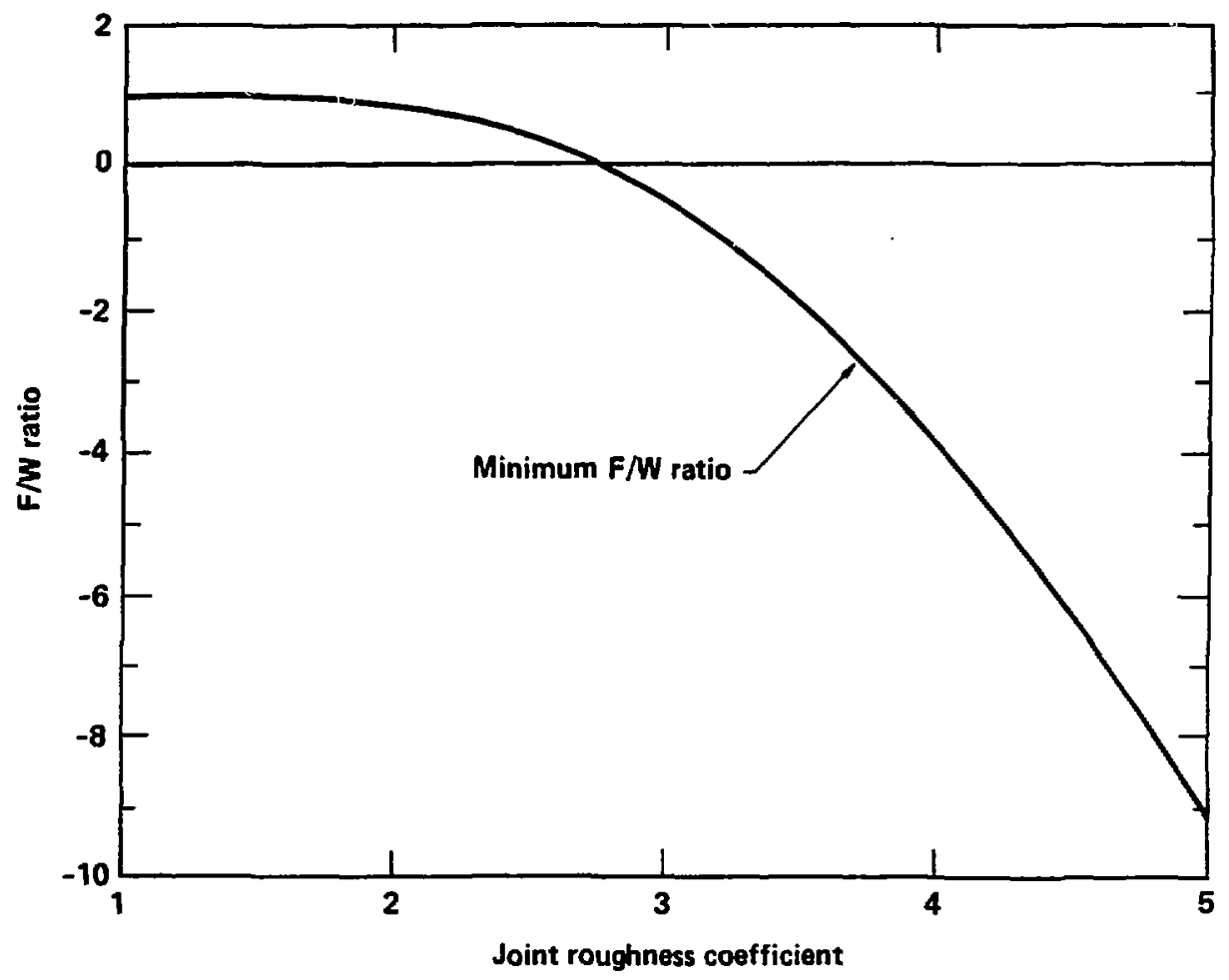

Figure 11a Variation of minimum F/W ratio with Joint Roughness Coefficient (JRC). 


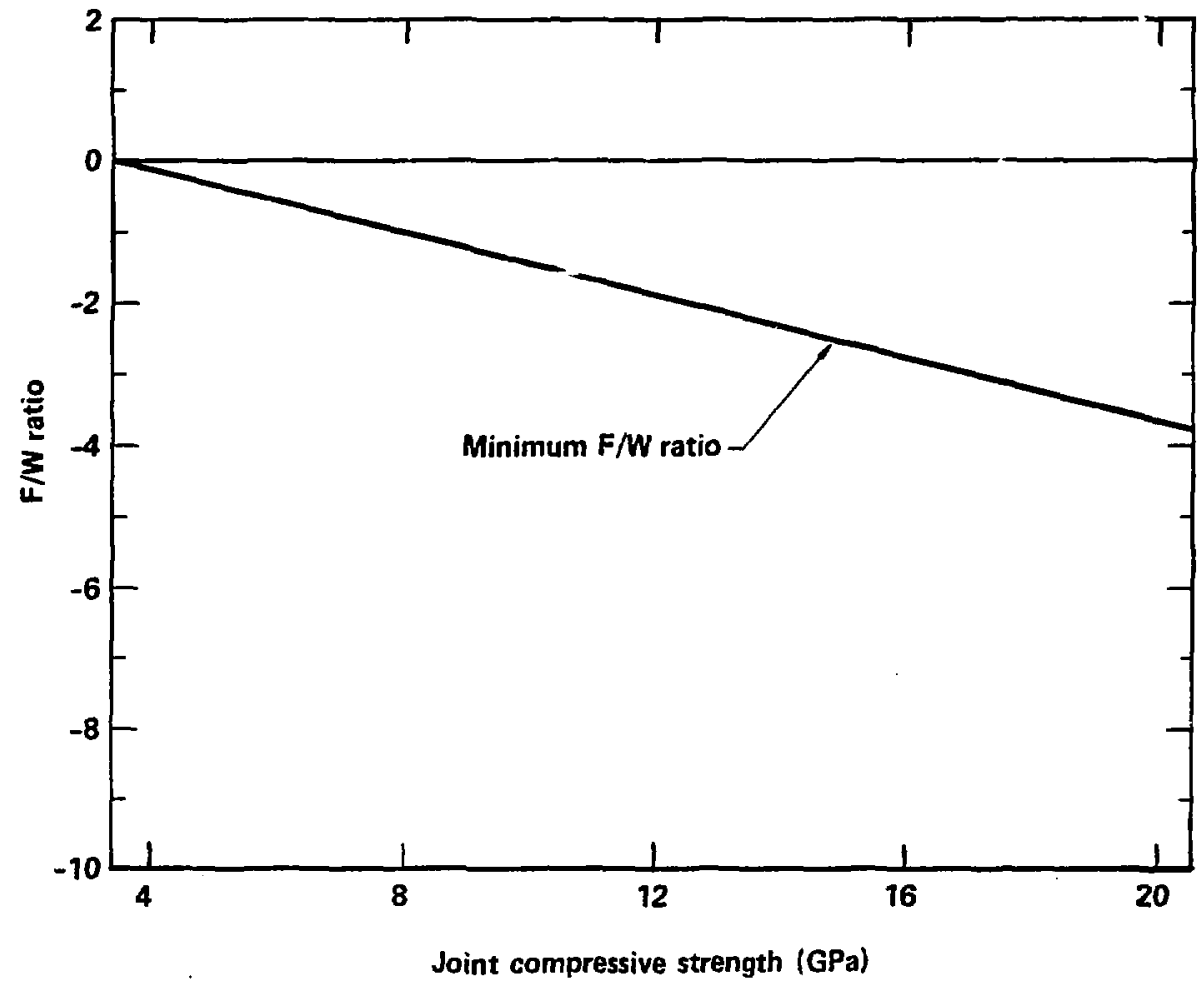

Figure 11b Variation of minimum F/W ratio with Joint Compressive Strength (JCS). 


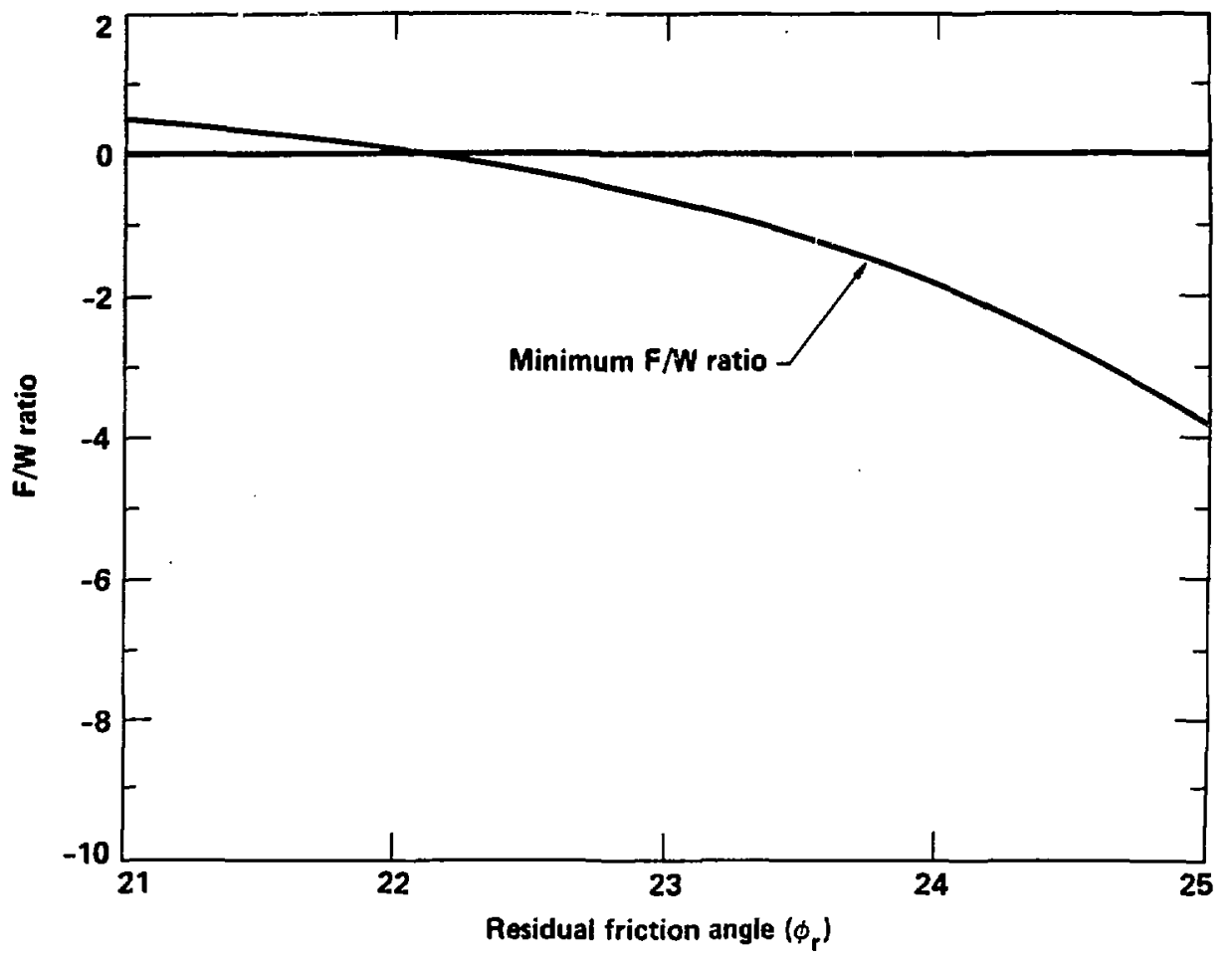

Figure 11c Variation of minimum $F / W$ ratio with residual friction angle $\left(\phi_{r}\right)$. 


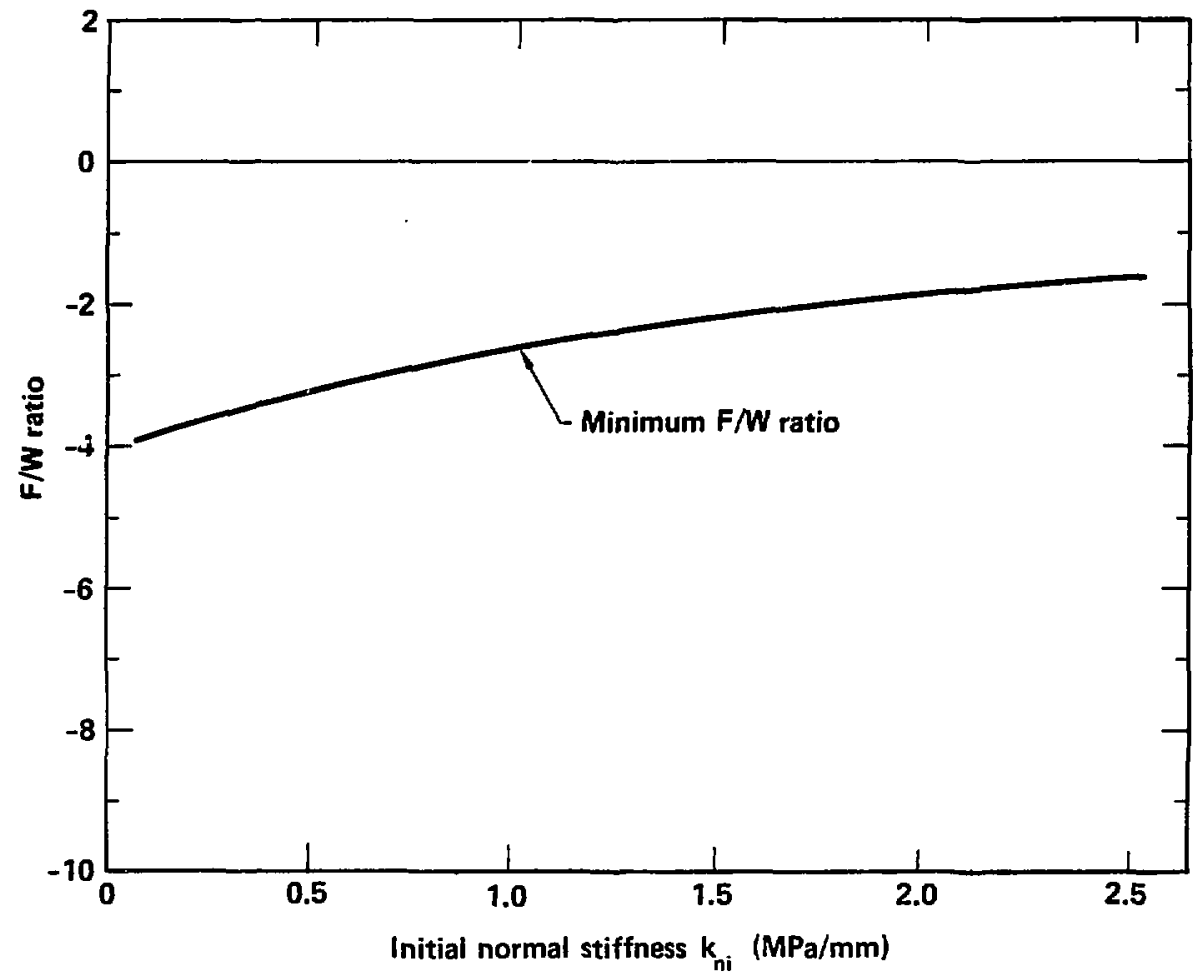

Figure 12 Minimum $F / W$ ratio versus initial normal stiffness. 


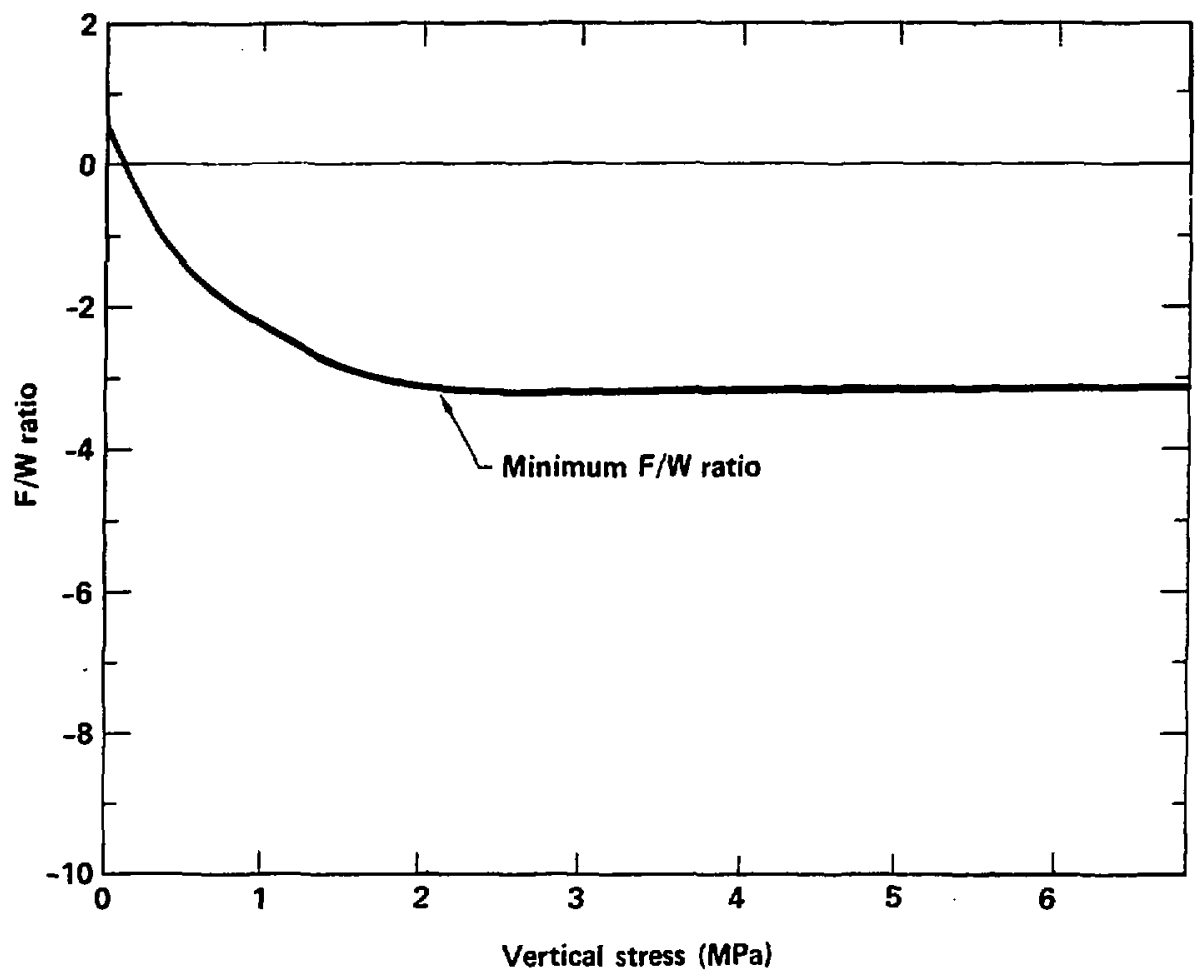

Figure 13 Minimum $F / W$ ratio versus in situ vertical stress magnitude with 0.5 lateral stress ratio. 


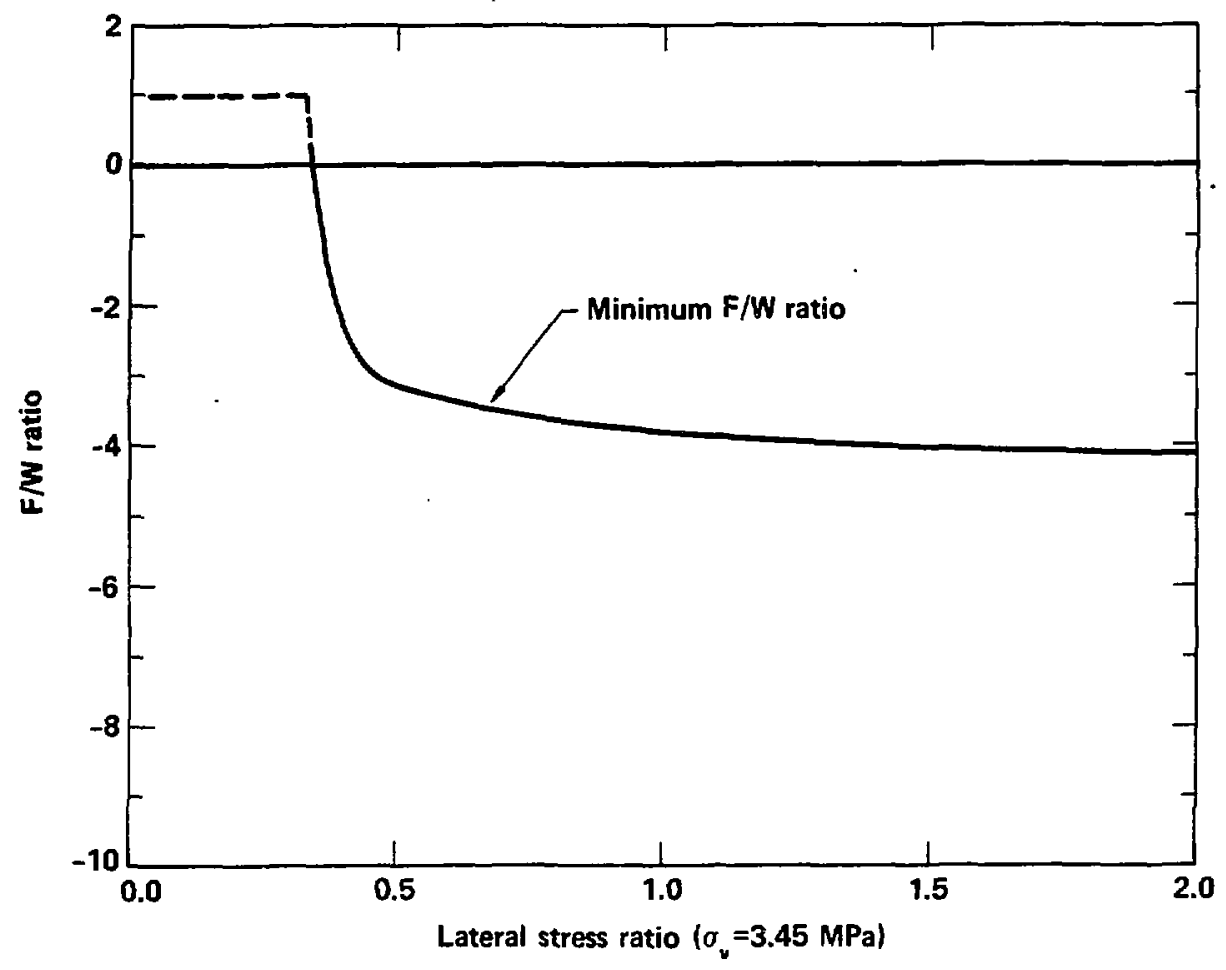

Figure 14 Minimum F/W ratio versus lateral stress ratio at constant in situ vertical stress. 


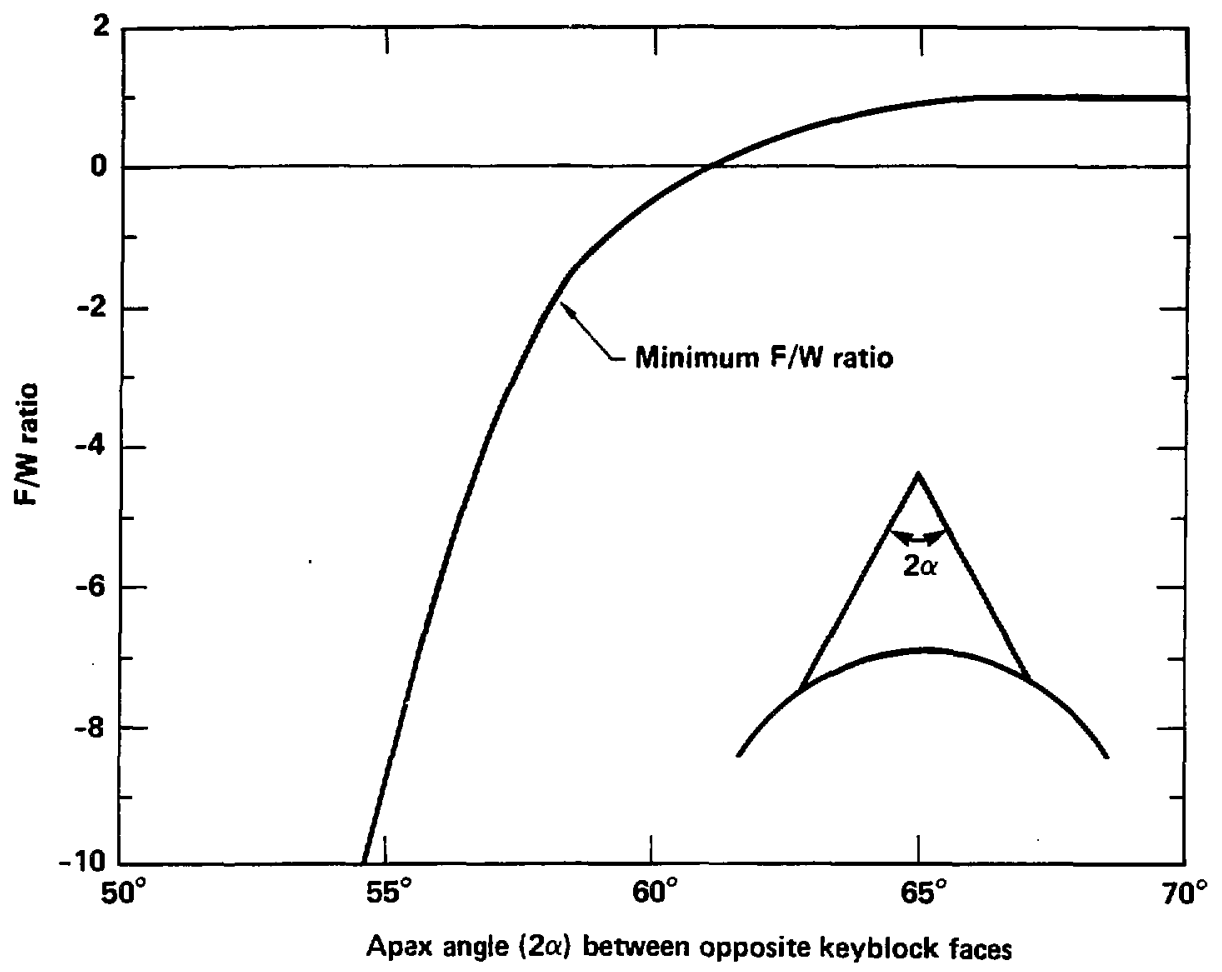

Figure 15 Minimum $F / W$ ratio versus acuteness of apex. 


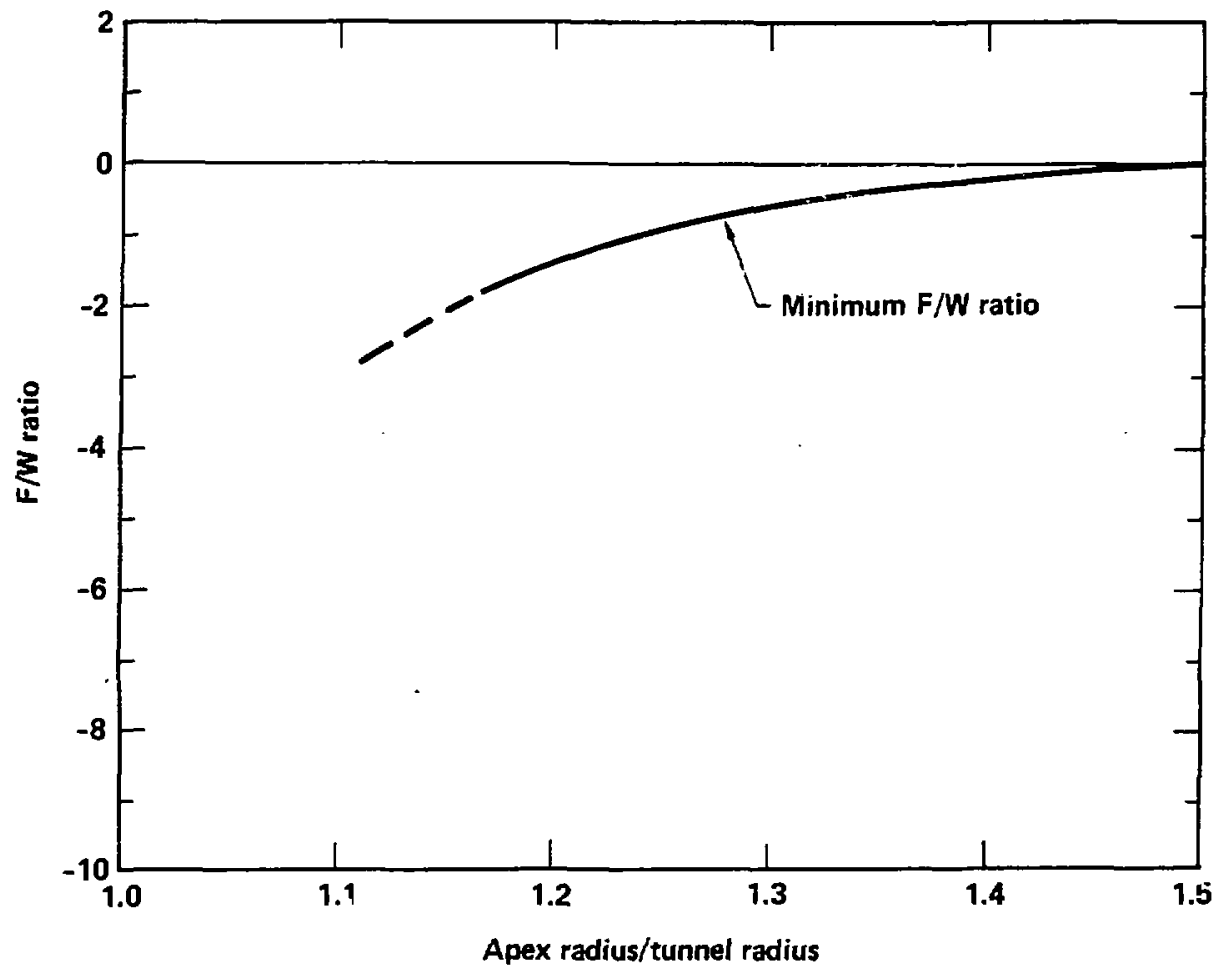

Figure 16 Minimum F/W ratio versus keyblock size (ratio of distance between tunnel axis and block apex to the radius of tunnel). 


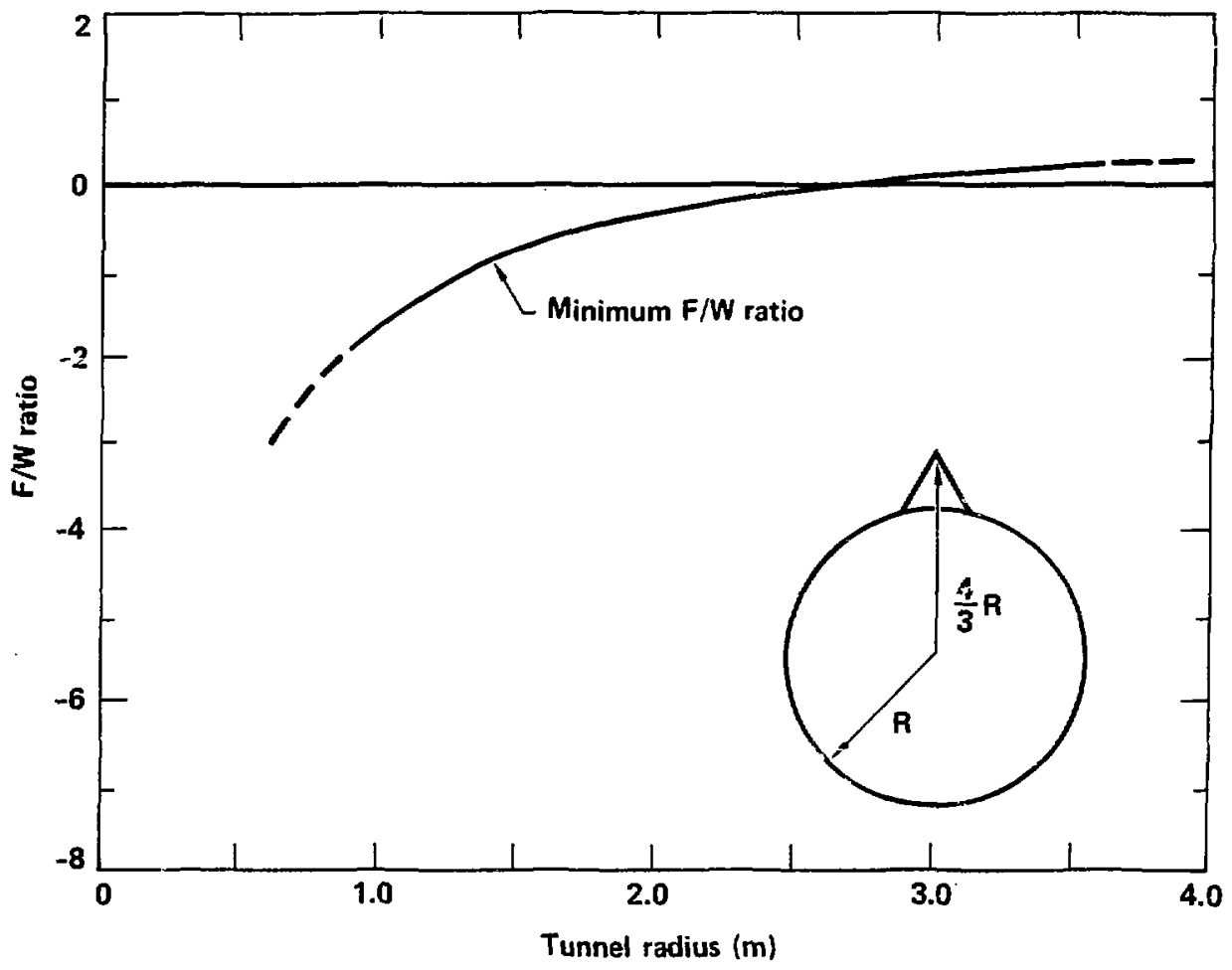

Figure 17 Minimum F/W ratio versus scale of keyblock and tunnel (radius to block apex $=4 / 3$ radius of tunnel). 


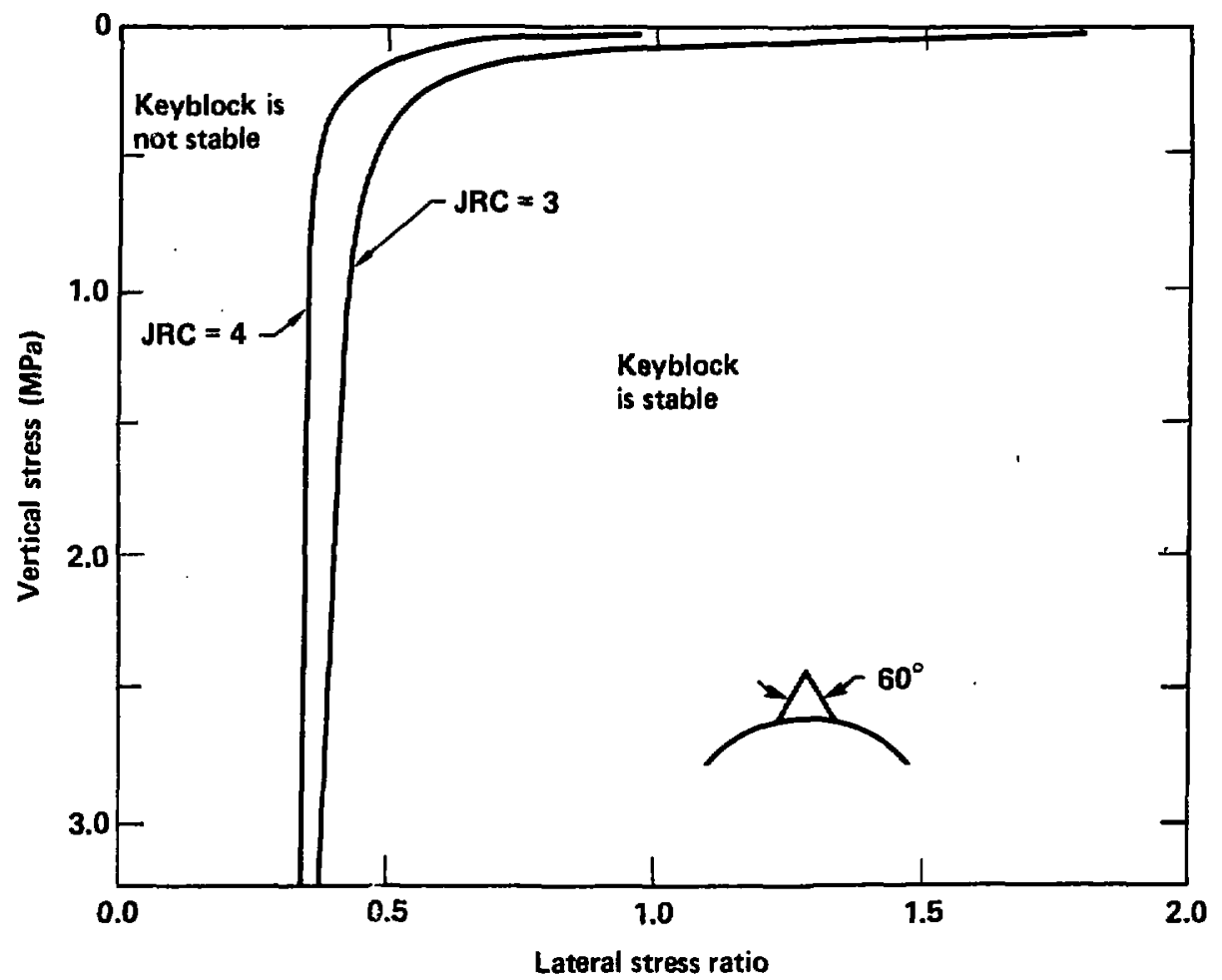

Figure 18 Lateral stress ratio required in situ for $F / W$ ratio of zero. 